\title{
Estudio comparativo de la intervención de grupos antidisturbios para el restablecimiento de derechos
}

\author{
Comparative study of the intervention of anti-riot groups for \\ the restoration of rights
}

\section{Estudo comparativo da intervenção de grupos anti-motins para a restauração de direitos}

\author{
Carolina Cardona Quiceno' \\ Edith Johana Puerto Joya ${ }^{2}$ \\ Karen Margarita Beltrán Peñuela ${ }^{3}$ \\ Ernesto Fajardo Pascagaza ${ }^{4}$ \\ Luis Carlos Cervantes Estrada ${ }^{5}$
}

Recibido: 24 de julio de 2020 Aprobado: 28 de agosto de 2020 Publicado: 12 de enero de 2021

Cómo citar este artículo:

Carolina Cardona Quiceno, Edith Johana Puerto Joya, Karen Margarita Beltrán Peñuela, Ernesto Fajardo Pascagaza \& Luis Carlos Cervantes Estrada. Estudio comparativo de la intervención de grupos antidisturbios para el restablecimiento de derechos.

DIXI, vol.23, $\mathrm{n}^{\circ} .1$, enero-junio 2021, 1-41.

DOI: https://doi.org/10.16925/2357-5891.2021.01.02

Artículo de investigación. https://doi.org/10.16925/2357-5891.2021.01.02

1 Abogada. Cadete, Escuela de Cadetes General Santander (ECSAN), Bogotá D.C., Colombia. ORCID: https://orcid.org/0000-0003-3775-7093.

Correo electrónico: cc.cardona00011@correo.policía.gov.co

2 Comunicadora Social. Especialista en Gerencia de Mercadeo, Universidad Politécnico Gran Colombiano. Cadete, Escuela de Cadetes General Santander (ECSAN), Bogotá D.C., Colombia.

ORCID: https://orcid.org/0000-0002-6817-212X.

Correo electrónico: edith.puerto@correo.policia.gov.co

3 Abogada. Cadete, Escuela de Cadetes General Santander (ECSAN), Bogotá D.C., Colombia. ORCID: https://orcid.org/0000-0001-5058-0355.

Correo electrónico: karen.beltran@correo.policia.gov.co

4 Coautor del artículo. Doctorando en Educación y doctorando en Filosofía. Magíster en Filosofía y magíster en Educación. Especialista en Filosofía y Educación. Licenciado en Teología y licenciado en Filosofía. Integrante del Grupo de Investigación ALETHEIA (categoría Colciencias A1). Investigador asociado, Escuela de Cadetes General Santander (ECSAN), Bogotá D.C., Colombia.

ORCID: https://orcid.org/0000-0003-1168-9512.

Correo electrónico: ernesto.fajardo9021@policia.edu.co

5 Coautor del artículo. Magíster en Docencia e Investigación Universitaria. Administrador policial. Director de Investigaciones ECSAN. Líder del Grupo de Investigación ECSAN (categoría Colciencias B). Investigador, Escuela de Cadetes General Santander (ECSAN), Bogotá D.C., Colombia. ORCID: https://orcid.org/0000-0002-5706-3251.

Correo electrónico: luis.cervante@correo.policia.gov.co 


\section{Resumen}

Objetivo: artículo producto de la investigación realizada por el Grupo de Investigación ECSAN acerca de la relación entre educación y pedagogía; tiene como fin analizar la intervención de los grupos antidisturbios de Colombia, Chile y Brasil en la protesta social desde la normativa nacional e internacional, un análisis de estructura y comparativo con la normatividad interna que regula el procedimiento a seguir en el control de multitudes, propiamente las fases antes, durante y después, sin olvidar la estructura estatal y de policía.

Metodología: investigación cualitativa, de análisis interpretativo, con apoyo en fuentes primarias y secundarias, y triangulación de la información.

Resultados: en el comparativo de la intervención en la protesta social, los organismos internacionales referencian una constante en el excesivo uso de la fuerza por parte de los grupos antidisturbios en los países objeto de estudio, lo cual se puede reflejar en denuncias y sanciones para el uniformado, la policía y el Estado en cuanto a los procedimientos de intervención de la protesta social y demás textos procedimentales que carecen de canales de diálogo por parte de los grupos antidisturbios.

Conclusiones: se plantea una propuesta institucional para la Policía Nacional de Colombia, en pro de la comunicación asertiva y previa con quienes ejercen su derecho a la protesta.

Palabras clave: derecho a la protesta social, intervención policial, mediación, normas de intervención, policía antidisturbios, uso de la fuerza.

\section{Abstract}

Objective: This article results from the research carried out by the ecsan Research Group on the relationship between education and pedagogy. It aims to analyze the intervention of riot control groups from Colombia, Chile and Brazil in social protest from national and international regulations. It consists of a structure and comparative analysis that includes the internal normativity that regulate the procedure to be followed in crowd control, properly the phases before, during and after, without forgetting the State and police structure.

Method: Qualitative research, consisting of interpretative analysis, supported in primary and secondary sources, and triangulation of information.

Results: In comparing the intervention in social protest, international organizations refer to a constant use of force by anti-riot groups in the countries under study, which can be reflected in complaints and sanctions for the uniformed, the police and the State regarding the intervention procedures of the social protest and other procedural texts that lack channels of dialogue on the part of the anti-riot groups.

Conclusions: An institutional proposal for the Policía Nacional de Colombia is suggested, in favor of an assertive and prior communication with those who exercise their right to protest.

Keywords: Right to Social Protest, Police Intervention, Mediation, Intervention Normativity, Anti-Riot Police, Use of Force.

\section{Resumo}

Objetivo: este artigo resulta da pesquisa realizada pelo Grupo de Pesquisa ECSAN sobre a relação entre educação e pedagogia. Tem como objetivo analisar a intervenção de grupos antimotim da Colômbia, Chile e Brasil em protestos sociais a partir de regulamentações nacionais e internacionais. Consiste numa estrutura e análise comparativa que inclui a normatividade interna que regula o procedimento a seguir no controlo de multidões, propriamente as fases antes, durante e depois, sem esquecer o Estado e a estrutura policial.

Método: Pesquisa qualitativa, composta por análise interpretativa, apoiada em fontes primárias e secundárias, e triangulação de informações. 
Carolina Cardona Quiceno, Edith Johana Puerto Joya, Karen Margarita Beltrán Peñuela, 3 Ernesto Fajardo Pascagaza, Luis Carlos Cervantes Estrada

Resultados: Ao comparar a intervenção em protesto social, as organizações internacionais referem um uso constante da força por grupos antimotim nos países em estudo, o que pode se refletir em denúncias e sanções para os uniformizados, a polícia e o Estado em relação à intervenção procedimentos do protesto social e outros textos processuais que carecem de canais de diálogo por parte dos grupos antimotins.

Conclusões: Sugere-se uma proposta institucional para a Policía Nacional de Colombia, a favor de uma comunicação assertiva e prévia com quem exerce seu direito de protesto.

Palavras-chave: Direito ao Protesto Social, Intervenção Policial, Mediação, Normatividade de Intervenção, Polícia Anti-Motim, Uso da Força.

\section{INTRODUCCIÓN}

En esta investigación, se han tomado algunos elementos como categorías relevantes, a saber: i) dinámicas por fases para la intervención de la protesta, ii) normas vigentes que rigen la intervención de la protesta social, iii) estandarización de la intervención, iv) percepción ciudadana y v) sanciones a la Policía. A los organismos de policía que se especializan en el control de la protesta social se les conoce como policía antidisturbios. En efecto, según el "Manual para el servicio en manifestaciones y control de disturbios para la Policía Nacional" (Resolución 03002 del 29 de junio de 2017), en Colombia el cuerpo de policía antidisturbios es un grupo operativo especializado que se encarga de las intervenciones especiales, en zonas rural y urbana del territorio colombiano, en el caso de aglomeraciones de público y de disturbios, motines u otras acciones que generen violencia y que afecten la seguridad y convivencia ciudadana'.

Desde 2011 la protesta social en América Latina se ha venido intensificando debido a la crisis de los regímenes políticos, las problemáticas sociales que desatan, las instituciones de mediación democrática, y a las expresiones sociales de molestia e inconformidad frente a decisiones gubernamentales o frente a formas de reproducción social que suscitan profundos desacuerdos.

La reacción de los Estados frente a tal intensificación de la protesta social ha sido frecuentemente cuestionada por sus métodos, y muchas veces se habla de "abuso de la fuerza", lo cual ha supuesto una percepción ciudadana de poca confianza hacia las instituciones. Si bien la acción de la fuerza pública para el control de la protesta social se justifica por la necesidad que tiene toda sociedad de mantener la estabilidad del orden público, es decir, las condiciones mínimas que garanticen la seguridad ciudadana, lo cierto es que diversos sectores sociales (generalmente aquellos que asumen lugares de oposición al régimen político) y organizaciones

1 Ministerio de Defensa Nacional. RESolución 02903 de 2017. Por la cual se expide el reglamento para el uso de la fuerza y el empleo de armas, municiones, elementos y dispositivos menos letales por la Policía Nacional. (Junio 23 de 2017). 
internacionales han denunciado ese abuso e incluso algunas posturas radicales han propuesto la abolición de la policía antidisturbios.

Según el esquema de análisis comparativo expuesto en el libro Monitor del uso de la fuerza letal en América Latina: un estudio comparativo de Brasil, Colombia, El Salvador, México y Venezuela, el abuso de la fuerza que se manifiesta como homicidios producidos por la intervención del Estado muestra que países como Brasil (con 7.3), Colombia (con 1.7) y México (con 1.2) están en las listas de mayor frecuencia del abuso de la fuerza. Esto indica que los problemas relacionados con el abuso de la fuerza letal por parte de las autoridades públicas es un problema que varía de país a país, pero que ya puede ser objeto de seguimiento como tendencia general².

Una perspectiva sistémica tendría que proporcionar un panorama del fenómeno sin presuponer que lo que ocurre como anomalía en realidad no se encuentra arraigado en la institución. La convicción de base deberá estar más bien aunada al esfuerzo por diagnosticar con más precisión la organización, formación y operación de los cuerpos policiales, con el fin de optimizar el ejercicio de sus funciones de acuerdo con las exigencias planteadas por las normativas nacionales e internacionales ${ }^{3}$. En la medida en que la investigación se dé a la tarea de examinar sin prejuicios y de valorar el ajuste de sus operaciones a las normas que regulan su legitimidad y legalidad, la seguridad ciudadana puede ser garantizada con mayor eficacia porque no solamente contaría con una positiva transparencia que fortalecería la formación integral de sus miembros, sino que además podría obtener un mayor nivel de confianza ciudadana y, con ello, una cooperación mucho más fluida por parte de la ciudadanía4

Es necesario reconocer que las causas de las protestas sociales y el proceder de la fuerza pública cambian de país a país; sin embargo, las denuncias frente al uso inadecuado de la fuerza por parte de la policía antidisturbios parece ser una constante. En Chile, los carabineros cuentan con Unidades de Control del Orden Público (cop); la policía colombiana tiene el Escuadrón Móvil Antidisturbios (Esmad); y en Brasil, cada estado tiene una policía militar (Batallón de Choque-Unidades de Choque).

En Colombia, el Escuadrón Móvil Antidisturbios (Esmad) fue señalado en los 448 casos de agresiones que generaron 3950 víctimas entre los años 2002 y 2014 . En Brasil, en 2017 la mayoría de las muertes fue provocada por la acción de las Policías Militares que causaron 2511 víctimas y en 2016 hubo 2207 víctimas. En Chile, el

2 Adrian Bergmann, Andrés Ruiz Ojeda, Carlos Silva Forné, Keymer Ávila, et al. MONITOR DEL USO DE LA FUERZA LETAL EN AMÉRICA LATINA: UN ESTUDIO COMPARATIVO DE BRASIL, COLOMBIA, EL SALVADOR, MÉXICO Y VENEZUELA. Fundación Ideas para la Paz; IIJ-UNAM. (2019).

4 Bergmann et al., supra, nota 7. 
Carolina Cardona Quiceno, Edith Johana Puerto Joya, Karen Margarita Beltrán Peñuela, 5 Ernesto Fajardo Pascagaza, Luis Carlos Cervantes Estrada

Informe Ginebra del 13 de diciembre de 2019 de la Oficina de Derechos Humanos de la oNu indica violaciones de derechos humanos por parte de los carabineros. Según el Ministerio Público chileno, hay investigaciones en curso relacionadas con veintiséis muertes ocurridas en el contexto de las protestas y las cifras del Ministerio de Justicia arrojan 4903 personas heridas hasta el 10 de diciembre de 2019, incluidos 2792 carabineros. El grado de impunidad es alto, ya que pocas veces los miembros de la policía antidisturbios hacen un uso ilegal de sus facultades y no son sancionados por las instituciones de las que hacen parte o por los tribunales judiciales, lo cual claramente estimula la comisión de delitos y la vulneración de los derechos ciudadanos.

El exceso de la fuerza, presuntamente, es un problema que les atañe a varios países que manifiestan su presencia, a veces de un modo más lesivo que otras, lo que genera consecuencias negativas en la legitimidad de las instituciones que se encargan de hacer cumplir la ley y afectan la seguridad de las ciudadanías. Uno de los problemas consiste en que las autoridades de policía y las autoridades judiciales, por lo general, se rehúsan a investigar las denuncias adelantadas por los ciudadanos frente los abusos de la fuerza cometidos por las autoridades públicas, con el argumento de que los hechos ocurridos se producen en escenarios de confrontación cuyas consecuencias letales aparecen como legítimas. Esto tiene relevancia para el presente trabajo si se adopta como perspectiva de análisis la configuración de los modelos de policía y su concreción en el terreno de las actuaciones concretas del personal policial ${ }^{5}$.

\section{OBJETIVO GENERAL Y OBJETIVOS ESPECÍFICOS}

Los objetivos que se formulan para el estudio permiten saber cuál es el horizonte comprensivo en el que este se inscribe, desde una perspectiva hermenéutica o de comprensión interpretativa ${ }^{6}$. En concordancia, el objetivo general de la presente investigación se formula de la siguiente manera: comparar la estructura funcional de los grupos antidisturbios de Colombia, Brasil y Chile como garante del orden público.

De acuerdo con la metodología empleada, se plantean tres objetivos específicos que permiten abordar aspectos puntuales de la problemática analizada, a saber:

5 Bergmann et al., supra, nota 7.

6 José Darío Herrera González. LA COMPRENSIÓN DE LO SOCIAL. HORIZONTE HERMENÉUTICO DE LAS CIENCIAS SOCIALES. Editorial Académica Española. (2009).

7 Ruth Sautu. TODO ES TEORÍA. OBJETIVOS Y MÉTODOS DE INVESTIGACIÓN. Editorial Lumiere. (2005). 
a) Describir la estructura interna de cada organización policial reconociendo las lógicas de mando y obediencia.

b) Analizar la normatividad nacional e internacional que regula las funciones de la policía en el control de la protesta mostrando su fundamento normativo.

c) Localizar los instrumentos que organizan la comprensión operativa de la intervención policial sobre la protesta social.

\section{MARCO TEÓRICO}

Se proporcionan nociones, conceptos y categorías que permiten interpretar el fenómeno estudiado, lo cual resulta de vital importancia para organizar el diseño de la investigación ${ }^{8}$ y para identificar qué es la unidad de análisis con la que se trabaja y cuál es la determinación teórica que produce: "La identificación de la unidad de análisis o de observación es un elemento muy importante en el desarrollo de la investigación, ya que representa el objeto de estudio; así como en dicha unidad es posible identificar las características que varían o variables a estudiar"9. Se describe analíticamente la protesta como un fenómeno social y la función que cumple la policía antidisturbios. De conformidad con esta doble exposición, es posible definir el conjunto de las categorías con las que se trabaja de acuerdo con el análisis de la información obtenida.

8 Ibid; Ruth Sautu, Paula Boniolo, Dalle Pablo y Rodolfo Elbert. La construcción del marco teórico en la investigación social. Ed. Ruth Sautu. MANUAL DE METOdología. CONSTRUCCIÓN DEL MARCO TEÓRICO, FORMULACIÓN DE OBJETIVOS Y ELECCIÓN DE LA METOdología. Clacso. (2005); Fernando Leal Carretero. Acerca de la teoría. ESPIRAL. EStUdios SobRe ESTAdo Y SOCIEDAD 57. 2013. Pág. 9-38. Disponible en http://espiral. cucsh.udg.mx/index.php/EEES/article/view/357

9 Joel Mendoza-Gómez. La teoría en la investigación científica: marco teórico, modelos y medición. Eds. Karla Annet y Cynthia Sáenz López. METodología PARA INVESTIGACIONES DE ALTO IMPACTO EN LAS CIENCIAS SOCIALES. Pág. 47-93. (2012). 
Carolina Cardona Quiceno, Edith Johana Puerto Joya, Karen Margarita Beltrán Peñuela, 7 Ernesto Fajardo Pascagaza, Luis Carlos Cervantes Estrada

\subsection{La protesta como fenómeno social}

En las investigaciones sociológicas de autores como Doug Mcadam, Sidney Tarrow y Charles Tilly ${ }^{10}$, la "política contestataria" aparece como una especie de interacción a veces episódica, otras veces pública y colectiva, que pone en tensión las relaciones entre la sociedad civil y el Estado. Los autores señalaban el carácter "contencioso" de la política y su especificidad con respecto a las otras manifestaciones más bien regulares o continuadas de la política. El campo de lo social es donde ocurre el fenómeno que es objeto de estudio: el control de la protesta social por parte de las autoridades públicas, el cual supone la existencia de un proceso político contencioso, un proceso en el que diversos actores sociales se movilizan llevando una serie de reivindicaciones que interpelan el orden político y social, y a la autoridad gubernamental, afectando los intereses de otros sectores de la sociedad que reclaman en favor de estos beneficios y la intervención del Estado. El estudio desarrollado trabaja la protesta social no como un "desorden" ni como un acto irracional efectuado por personas "inadaptadas", sino como la manifestación del inconformismo social cuya resolución no se lograría mediante la prohibición o la fuerza, sino que requiere de mediaciones públicas que atiendan a su conflictividad originaria"11.

Todos los fenómenos sociopolíticos conflictivos, sean protestas, huelgas, insurrecciones, etc., se encuentran en medio de la tensión entre el Estado (orden público institucional instaurado en la Constitución) y la sociedad (conjunto de estructuras y sistemas de interacción organizada o espontánea que se desarrolla en un plano distinto aunque no independiente de las instituciones públicas) ${ }^{12}$. Velasco ${ }^{13}$ denomina procesos de contestación a aquellos que suelen poner en entredicho las estructuras del poder, señalando el carácter desproporcionado de su distribución en la sociedad, y es esta desproporción lo que impulsa a determinados sectores de la sociedad civil a equilibrar las cargas de poder. Con ello, el ejercicio de la ciudadanía adquiere un

10 Doug Mcadam, Sidney Tarrow y Charles Tilly. DYNAmics of CONTENTION. Cambridge University Press. (2001).

11 Ibid.

12 Pedro Luis Lorenzo Cadarso. Principales teorías sobre el conflicto social. NORBA: REVISTA DE HISTORIA 15. 1995. Pág. 237-253; Asel Mercado Maldonado y Guillermo González Velásquez. La teoría del conflicto en la sociedad contemporánea. ESPACIos PúBLIcos 21. Febrero de 2008. Pág. 196-221; Germán Silva García. La teoría del conflicto. Un marco teórico necesario. PROLEGÓMENOS, DERECHOS Y VALORES 22. Juliodiciembre de 2008. Pág. 29-43; Benjamín Tejerina Montaña. Las teorías sociológicas del conflicto social. Algunas dimensiones analíticas a partir de K. Marx y G. Simmel. REIS: REVISTA ESPAÑola de INVESTIGACIONES SOCIOLógICAS 55. 1991. Pág. 47-63.

13 Marcela Velasco Jaramillo. Cambio institucional y protesta social en Colombia 19642000: análisis de series de tiempo. COLOMBIA INTERNACIONAL 63. Enero de 2006. Pág. 70-87. 
significado mucho más amplio. No importa si esta contestación tomó al Estado como medio o como adversario, su permisión solo puede contribuir a la democratización de la sociedad, mientras que, por el contrario, su represión tiene como consecuencia el ejercicio de un régimen autoritario. Por su parte, la capacidad del Estado supone todos los procesos que le permiten monopolizar el uso de la fuerza, controlar el uso de los recursos y disciplinar el comportamiento de las personas.

En varios estudios ${ }^{14}$, se muestra cómo tales procesos se ven constantemente determinados por los intereses de las élites políticas y por las situaciones locales, nacionales e internacionales que organizan las estructuras del poder. Por supuesto, estos procesos de consolidación del Estado también se ven frecuentemente limitados por los procesos o las acciones de contestación; pero lo interesante es, como lo señala Velasco ${ }^{15}$, que el origen de las instituciones se encuentra justamente ahí, en los procesos en los que el Estado y la sociedad civil entran en un conflicto abierto, y en la medida en que los resultados de ese conflicto por lo general favorecen a los sectores sociales más poderosos, los actores sociales que llevan a cabo una política de contestación tienden a distanciarse de las instituciones y a poner en duda su legitimidad. En estas condiciones, podría decirse que la capacidad ciudadana alude a las habilidades que tiene la población para ejercer sus derechos y construir su propio bienestar haciendo valer intereses que desde las bases sociales entran en confrontación con la clase política que ostenta el control del Estado.

La protesta social es un medio legítimo para la reivindicación de derechos de cualquier índole, y se encuentra constitucional y legalmente protegido. El derecho a la protesta social se ha entendido como un conjunto de derechos fundamentales de: 1) asociación o reunión pacífica; 2) libertad de expresión; y 3) huelga y otras garantías relacionadas, todo en la ejecución de circunstancias específicas de tiempo, modo y lugar. Cuando se habla de protesta social, se presenta siempre una dicotomía entre la protección de este derecho y la necesidad de garantizar la seguridad ciudadana y el orden constitucional, que eventualmente podrían verse afectados en su ejercicio ${ }^{16}$.

En la medida en que la protesta social constituye un "medio legítimo", este goza de un determinado nivel de aceptación política y de legalización en el ámbito de la esfera pública. El derecho a la protesta social aparece como síntesis de otros derechos a los que se les considera fundamentales (asociación, libertad de expresión,

14 Evelyn Huber. Assesments of state strength. Ed. Peter H. Smith. LATIN AMERICA IN COMPARATIVE PERSPECTIVE: NEW APPROACHES TO METHODS AND ANALYSIS. Westview Press. (1995). Pág. 35-69; Mcadam et al., supra, nota 15.

15 Velasco, supra, nota 18.

16 Camilo Burbano. ¿CÓMo SE RIGE LA PROTESTA PACíFICA EN COLOMBIA? EL EJERCICIO Y LA GARANTÍA DE UN DERECHO FUNDAMENTAL. Fundación Ideas para la Paz. (2008). 
Carolina Cardona Quiceno, Edith Johana Puerto Joya, Karen Margarita Beltrán Peñuela, 9 Ernesto Fajardo Pascagaza, Luis Carlos Cervantes Estrada

huelga, etc.), esto es, derechos inalienables que proporcionan la base normativa para la estructuración de otros derechos.

\subsection{La policía antidisturbios}

La policía es una institución pública encargada de mantener la seguridad ciudadana; y en cuanto ejecutora de una función específica en el sistema social, se encuentra jurídicamente regulada, políticamente orientada y jerárquicamente dirigida ${ }^{17}$. Al ser esta institución, por su esencia, la encargada de la seguridad de los ciudadanos, su articulación estructural respecto a otras instituciones y a otras funciones sociales, los conceptos de "modelo de policía" y "modelo de seguridad" hace referencia al conjunto estructural o sistémico en el cual se articula la policía y sus funciones de seguridad con el resto del sistema social. Esto implica, a su vez, las instancias que determinan la regulación normativa, la dirección interna de la institución, la articulación interinstitucional, y los medios y los procedimientos con los cuales la policía cumple sus funciones. Al hablar de modelo policial, se pone de presente el conjunto estructural que determina la operatividad puntual de la policía y de sus miembros como agentes o funcionarios de esta; podría decirse que el modelo policial es aquello que constituye un paradigma o una racionalidad que pauta el funcionamiento de la institución.

Cada modelo de policía (modelo gubernativo, modelo profesional, policía comunitaria, modelo de orientación problemática, modelo de inteligencia, etc.) resulta a partir de una evolución sistemática de la institución policial según las particularidades de cada sociedad, es decir, según las características que el sistema social considerado presente a propósito de su cultura policial18. La "cultura policial" marca entonces un ámbito de los modelos de policía que desborda por completo el diseño institucional y las regulaciones jurídicas que van configurando una serie de pautas externas, una ca-

17 Soufiane Ouaarab Essadik. LA REINVENCIÓN DE LA POLICÍA: HACIA UN NUEVO PARADIGMA PARA EL PENSAMIENTO DEL GOBIERNO DE LA ACTUACIÓN POLICIAL. Universitat Autònoma de Barcelona. (2015); Francesc Guillén Lasierra. MODELOS DE POLIcíA Y SEGURIDAD. Bosch. (2016); Wilford Méndez Rojas y José Aristóbulo Rodríguez Salazar. Relación de la policía con el resto de la sociedad: práctica policial, territorio y bios [tesis de maestría, Pontificia Universidad Javeriana]. (2010); Francesc Reales. La gestión de la alteración del orden en espacios públicos: un desafío policial. REVISTA DE DERECHO PENAL Y CRIMINOLOGía 10. 2013. Pág. 493-523.

18 Maria Laura Bianciotto. A PROPósito deL CONCEPTO DE "(SUB) CULTURA POLICIAL". PRIMEROS ELEMENTOS PARA UN POSIBLE DEBATE. IX CONGRESO ARGENTINO DE ANTROPOLOGíA SOCIAL. (2008). Editorial Universidad Nacional de Misiones; Santiago Ginés Nabaes Jodar. El concepto de cultura policial. UNIDAD socIOLóGICA 12. Febreromayo de 2018. Pág. 88-97; María Eugenia Suárez de Garay. LOS PoLicíAS: UNA AVERIGUACIÓN AONTROPOLÓGICA. Iteso. (2016). 
dena de prácticas estructuradas en cuya articulación sistémica convergen múltiples factores del orden sociocultural. De acuerdo con esta perspectiva, puede decirse que el modelo policial es una realidad histórica y, por lo tanto, no es un aspecto naturalizado e inmune a las crisis o a las modificaciones que el sistema social y el subsistema cultural le van pautando a su funcionamiento; en este sentido, el modelo de policía es también un conjunto de instituciones, racionalidades y procedimientos en constante adaptación a la evolución de los sistemas sociales.

La policía antidisturbios o policía antimotines constituye una unidad u organismo que se especializa en el control de multitudes, lo cual implica la dispersión de las manifestaciones que no gozan de una autorización pública o que en su ejercicio no atienden las normas que las regulan. El restablecimiento de los derechos de la ciudadanía se establece con base en sus funciones. Existen también otras actividades que la policía antidisturbios cumple en distintos países del mundo, a saber: hacer cumplir las órdenes de desalojo en predios que han sido ocupados ilegalmente o contener confrontaciones violentas entre colectividades sociales ${ }^{19}$. La policía antidisturbios está encargada de "gestionar a las multitudes" y cumple una función que, en condiciones de abierta contingencia e incertidumbre, exige una actuación lo suficientemente planificada y flexible para brindar seguridad a los participantes que intervengan y, así mismo, exige adaptarse a situaciones cambiantes en la medida en que su función específica consiste en el restablecimiento de los derechos, es decir, asegurar la normalidad de la vida cotidiana y, con ella, las garantías de la seguridad ciudadana. Según sea la naturaleza de la situación, tal función debe recurrir a procedimientos que pueden ser: a) de "prevención", b) de "control" o c) de "restauración"20. Con base en estas acotaciones, a continuación se definen las categorías y subcategorías que permiten obtener, organizar y analizar la información.

\section{Metodología de inVestigación}

Esta investigación constituye un estudio cualitativo en el que se pretende analizar y comprender interpretativamente (análisis hermenéutico) la actuación del control de la protesta social en Colombia, Chile y Brasil; y también cuáles serían las condiciones de protocolos para su mejoramiento. Se trabaja con fuentes primarias, fuentes secundarias y entrevistas a profundidad cuya información ha sido organizada por medio de una matriz de análisis en la que se determinan variables que permiten, en

19 Essadik, supra, nota 22; Méndez y Rodríguez, supra, nota 22.

20 Reales, supra, nota 22. 
primer lugar, diseccionar analíticamente el fenómeno descomponiéndolo en sus diversos elementos $y$, en segundo lugar, reconstruir estructuralmente las relaciones orgánicas entre sus elementos captando con ello la realidad compleja que se pone de manifiesto.

Con base en la documentación obtenida en el ejercicio de investigación y en entrevistas a profundidad, el análisis trabaja con un mapa que organiza el proceso de investigación en sus fases de recolección, organización y análisis de información. El mapa ha sido diseñado para funcionar como dispositivo del análisis comparativo en relación con la problemática enunciada a propósito de la intervención de la policía antidisturbios como agente de control en la protesta social y en la perspectiva del restablecimiento de los derechos de la ciudadanía. Está compuesto por siete fases secuenciales cuyo desarrollo permitirá el cumplimiento de los objetivos trazados:

1. Área y línea de investigación: Se trata del "servicio de policía y procedimientos policiales" como área y línea institucional de investigación, la cual comprende el estudio de la intervención de la policía antidisturbios en el control de la protesta social.

2. Enfoque cualitativo: La perspectiva hermenéutica realiza un análisis compresivo e interpretativo.

3. Diseño y aplicación de instrumentos: Construcción de dos matrices (matriz de información y matriz de análisis). Se busca interpretar el fenómeno de la protesta social con las herramientas metodológicas según las categorías y subcategorías, así como por países, y según el análisis documental y de las entrevistas a profundidad, con el fin de adquirir información que no fue posible obtener en internet; así mismo, se busca conseguir aspectos relevantes para la investigación de forma veraz y oportuna. Los entrevistados son miembros de la Policía del grupo objeto de estudio. En Colombia, se entrevista al señor oficial teniente coronel Henry Roger De Castro Santander, que está en la especialidad del Esmad hace quince años, ha pasado por diferentes cargos dentro de la especialidad y actualmente se desempeña como subcomandante del Esmad; y se entrevista al señor coronel de la reserva activa Carlos Alberto Meléndez Caicedo, con trayectoria de 32 años en la institución, se desempeñó como comandante de la Fuerza Disponible, entre otros, y como último cargo fue subdirector de Seguridad Ciudadana, tuvo bajo su liderazgo grupos como el Esmad. En Chile, se entrevista a un sargento que lleva dieciocho años en la institución, es instructor en la Escuela de Suboficiales de Carabineros, hizo parte del 
cop hasta hace unos meses, se reserva el nombre del sargento a solicitud propia. En Brasil, se entrevista al señor oficial de la Policía Militar del estado de Ceará, teniente coronel Alkimar Sampaio De Souza, quien actualmente se desempeña como asesor parlamentario de seguridad del director general de la Policía Militar.

4. Análisis de la información: Consignar la información en una matriz en la que se diferencien los elementos del fenómeno objeto de estudio; establecer la conexidad de los elementos descubriendo las diferencias y las semejanzas de los países en comparación.

5. Proceso de intervención a la protesta social de la policía: En esta se enmarca la unidad de análisis: "el proceso de intervención a la protesta social de la policía", de la cual se derivan las categorías y subcategorías.

6. Conclusiones: Consiste en un cierre ordenado de la información, teniendo en cuenta los resultados obtenidos y mostrando los puntos importantes de la investigación.

7. Diseño de la propuesta Dirección de Seguridad y Convivencia Ciudadana: Esta fase consiste en formular una propuesta que aporte a una mejor prestación del servicio, capacitando y estructurando la intervención en su etapa previa por parte de la policía antidisturbios.

\section{a. Análisis comparativo}

En este acápite, se presentan los resultados de la investigación una vez se haya obtenido, organizado y analizado la información. Se presentará una síntesis de cada una de las categorías diseñadas para el análisis, conjugando las semejanzas y las diferencias de la protesta social en cada país (Colombia, Chile y Brasil).

\section{DINÁMICA POR FASES PARA LA INTERVENCIÓN DE LA PROTESTA}

En principio, Colombia, Chile y Brasil comparten el hecho de que la emergencia o aparición de la policía antidisturbios ha obedecido a una necesidad pública de establecer controles a la protesta social, partiendo de que no todas las personas que participan en las protestas lo hacen de manera pacífica. Lo que puede señalarse desde ya es que el análisis resalta más las diferencias que las similitudes. Una diferencia clara 
Carolina Cardona Quiceno, Edith Johana Puerto Joya, Karen Margarita Beltrán Peñuela, 13 Ernesto Fajardo Pascagaza, Luis Carlos Cervantes Estrada

corresponde al régimen político, lo cual marca distinciones respecto al papel de la policía en una democracia.

Otra diferencia tiene que ver con la organización republicana, ya que mientras Brasil es un Estado federal (con repercusiones en las lógicas de la descentralización de la policía y de las relaciones entre esta y el ejército), Colombia y Chile se organizan en torno a un Estado central. Dando continuidad a estas diferencias, mientras que en Colombia se ha consolidado una policía completamente independiente del ejército, en Chile y Brasil existe una cooperación entre estos dos organismos de seguridad.

En Brasil existe la Policía Militar, donde hay una Unidad de Choque para cada estado; en Colombia existe el Esmad, creado específicamente para el control de la protesta social; en Chile se encuentra la prefectura de Fuerzas Especiales de Carabineros, conformados como cuerpos especializados en el ejercicio de ese control. Mediante Orden General 2731 del 3 de enero de 2020, el nombre de Fuerzas Especiales fue modificado a Unidades de Control del Orden Público (COP); esta especialidad, antes de la alteración del orden público que sufrió Chile a finales de 2019, no contaba con estos grupos en el territorio nacional, pero debido a la contingencia se dio la estructuración de estos grupos en las demás regiones. Sin embargo, el cop cuenta con el apoyo del Grupo de Operaciones Policiales Especiales (GOPE), una fuerza que solo opera en el territorio que abarca a la ciudad capital Santiago de Chile.

En Colombia, el Esmad es la única fuerza especial que se denomina antidisturbios, lo cual la caracteriza explícitamente como fuerza policial especializada en el control de multitudes. Esto marca un elemento paradigmático en el continente en cuanto a los modelos de policía; sobre todo si se toma en cuenta que, según la lógica evolutiva de los sistemas sociales, un sistema social (en este caso el modelo de policía como algo interno a la estructura social) es tanto más desarrollado cuanta más diferencia y especialización tienen sus funciones.

Las instituciones policiales de Brasil, Chile y Colombia son miembros de la organización internacional Comunidad de Policías de América (Ameripol) desde su creación en el año 2008. Este es un mecanismo de cooperación entre países miembros, cuyo fin es fortalecer una colaboración policial en diferentes aspectos; así mismo, tener una efectividad en intercambio de información con fines de inteligencia, investigación criminal y asistencia judicial que permiten la articulación y un apoyo entre las policías (en pro de la lucha contra el crimen organizado y los delitos en el ámbito internacional).

Los países objeto de comparación en la presente investigación tienen una organización de dirección distinta. En Colombia, la estructura institucional se organiza así: la Dirección General de la Policía Nacional, la Subdirección General, la Dirección 
de Seguridad Ciudadana (Disec) y los Comandos Unidades Operativas Especiales, al cual pertenece la Unidad Nacional Antidisturbios (Unadi), además de su estructura de comando de unidad y subcomando, ubicadas en ocho regionales y distribuidos en veintinueve escuadrones (en las principales ciudades y capitales).

En Brasil, la Policía Militar es estatal y es responsable de la preservación del orden; tiene vinculación con la Secretaría de Seguridad Pública, y seguido a ello tiene autonomía y competencia el director de la Policía Militar en su estado ya que es independiente; pertenece a un Comando de Operaciones de Choque que forma parte de unos batallones según el estado, las necesidades y las problemáticas que se presenten.

Chile tiene estructurado el grupo de cop de la siguiente forma: la Dirección General-Subdirección de donde se desprende la Dirección Nacional del Orden y Seguridad, seguido de la Jefatura de Zona Metropolitana, luego Zona Control Orden Público y este se divide en dos dentro de la ciudad capital: Zona Este (28 Comisaria) y Zona Oeste (40 Comisaria).

El modelo de policía se organiza, en esta perspectiva, de acuerdo con la evolución histórica de la policía en estos países, y ha facilitado un mayor grado de amplitud en sus funciones gracias a la incorporación de lineamientos internacionales a la racionalidad operativa de la institución en cada uno de ellos. Además, Colombia, Chile y Brasil cuentan con escuelas de formación donde se prepara al personal de policía en el entendimiento y el acatamiento de tales lineamientos internacionales.

\section{NORMAS VIGENTES QUE RIGEN LA INTERVENCIÓN DE LA PROTESTA SOCIAL}

Este comparativo permite obtener similitudes y diferencias para cada subcategoría (normas de derechos humanos, normas de procedimientos y normas de protección). Respecto a las normas internacionales, Colombia, Brasil y Chile comparten obligaciones y compromisos relacionados con el acatamiento de las normas internacionales de derechos humanos en correspondencia con las exigencias de la Organización de las Naciones Unidas (ONU) y otros organismos intergubernamentales y ONG como el Comité Internacional de la Cruz Roja (CICR).

Estas normas internacionales pueden ser consideradas como lineamientos condicionales, los cuales se encuentran inscritos en la Declaración Universal de los Derechos Humanos, adoptada por la Asamblea General de las Naciones Unidas (Resolución 217 A-III) el 10 de diciembre de 1948, codificados especialmente en los 
Carolina Cardona Quiceno, Edith Johana Puerto Joya, Karen Margarita Beltrán Peñuela, 15 Ernesto Fajardo Pascagaza, Luis Carlos Cervantes Estrada

artículos 1, 2, 3, 5 y 20. Así mismo, esos lineamientos están contenidos en el Pacto Internacional de Derechos Civiles y Políticos adoptado por la Asamblea General de las Naciones Unidas (Resolución 2200 A-XXI), en especial los artículos 2, 6, 7, 8.1, 8.2, 9, 12 y 21; por la Declaración Americana de los Derechos y Deberes del Hombre, adoptada por la Organización de los Estados Americanos (OEA) en 1948, en especial los artículos 1, 2, 21 y 31; por la Convención Americana sobre Derechos Humanos (también conocida como Pacto de San José de Costa Rica), especialmente los artículos 2, 4, $5,7,13,15,24$ y 27.

Existen, además, otras fuentes del derecho internacional público que se integran a dichos lineamientos: la observación general sobre el artículo 19 ("Libertad de Opinión y Libertad de Expresión"), adelantada por el Comité de Derechos Humanos de la onu y la Convención Internacional sobre la Eliminación de Todas las Formas de Discriminación Racial, puntualmente el artículo 5; la Carta Democrática Interamericana, aprobada el 11 de septiembre de 2001, artículo 4; la Carta Social de las Américas aprobada por la OEA el 4 de junio de 2012, artículo 30; y la Convención Interamericana para Prevenir, Sancionar y Erradicar la Violencia contra la Mujer (Convención de Belém do Pará), artículo 4. En todas estas fuentes del derecho internacional público, la libertad de expresión, el derecho de libre asociación, el derecho de huelga y otras garantías se inscriben como determinaciones normativas que protegen el derecho a la protesta como un derecho de las ciudadanías en los Estados democráticos. Todas estas fuentes han sido suscritas por los países que son revisados en el análisis comparativo de esta investigación y resultan de vital importancia para comprender las orientaciones normativas que la institución policial, según la estructura jurídica de su modelación particular, debe acatar para conservar sus fundamentos de legitimidad y legalidad.

Hay normas como el Código de Conducta para Funcionarios Encargados de Hacer Cumplir la Ley, adoptado por la Asamblea General de las Naciones Unidas en su Resolución 34/169 del 17 de diciembre de 1979, y los Principios Básicos para el Empleo de la Fuerza y Armas de Fuego, adoptados en el VIII Congreso de las Naciones Unidas sobre Prevención del Delito y Tratamiento del Delincuente, celebrado en La Habana (Cuba) entre el 27 de agosto y el 7 de septiembre de 1996. En el principio 9, se establecen los alcances y las limitaciones del uso de armas de fuego de acuerdo con circunstancias de excepcionalidad. Se establece el uso de armas de fuego (el cual es potencialmente uso de la fuerza letal) como ultima ratio, es decir, como el último recurso al que los funcionarios encargados de hacer cumplir la ley pueden recurrir. Se trata entonces de una normativa que impone alcances y límites a la acción policial sobre la base de una especificación de las circunstancias en las que es lícito o no hacer uso de las armas de fuego, considerando que ese uso solo se corresponde con la 
defensa del único bien mayor, a saber: la vida e integridad de la persona humana. Por lo tanto, el uso de armas de fuego no puede ser legítimo ni legal arguyendo cuestiones de orden o de obediencia a la autoridad.

Respecto a los lineamientos no condicionales, el Centro Regional de las Naciones Unidas para la Paz, el Desarme y el Desarrollo en América Latina y el Caribe (Unlirec) reconoce, en las fuentes del derecho internacional consuetudinario, otra dimensión del derecho internacional público: existe una provisión perentoria e irrestricta frente a la tortura y frente a otros tratos o penas crueles, inhumanas o degradantes que debe respetarse con independencia de los compromisos convencionales asumidos por cada uno de los Estados miembros ${ }^{21}$.

Son varios los instrumentos internacionales relacionados con la conducta policial y recomendados por las ONG (los cuales, por supuesto, no poseen un carácter vinculante). Entre ellos está el CICR, entidad independiente e imparcial que presta asistencia humanitaria en situaciones de conflicto armado, y que realiza actividades cuyo objetivo es lograr que las normas de derechos humanos y los principios humanitarios, en la medida en que son aplicables a regulación normativa de la función policial, se integren en la formación y el entrenamiento de los funcionarios encargados de hacer cumplir la ley ${ }^{22}$.

Además de lo anterior, los pactos referidos a la protección general de los derechos humanos, en cuanto estos son reglas mínimas para efectuar operativamente, otorgan relevancia paradigmática en lo que respecta al modelo de policía a otro instrumento: el Código de Conducta para Funcionarios Encargados de Hacer Cumplir la Ley, adoptado por la Asamblea General de las Naciones Unidas mediante Resolución 34/169 del 17 de diciembre de 1979²3. Todos los países que son objeto de la presente comparación han adoptado estos lineamientos.

En cuanto a las normas de protección como segunda subcategoría, lo primero que puede constatarse es que los ordenamientos constitucionales de cada uno de los países objeto de comparación reflejan la impronta paradigmática del Derecho Internacional de los Derechos Humanos. Las fuerzas militares y policiales que representan los cuerpos de seguridad para garantizar la libertad y seguridad como derechos reconocidos por la comunidad internacional y por los Estados nacionales (Colombia, Chile y Brasil), entendidos como garantes del bienestar social de la ciudadanía, deben ejecutar y acatar las normativas gubernamentales que rigen la

21 Fernando Martínez Mercado. Investigación aplicada. Uso de la fuerza. DocUMENTO DE tRABAJO N 4. Centro de Estudios en Seguridad Ciudadana. (2016).

22 Ibid.

23 Organización de las Naciones Unidas (ONU). cóDIGO DE CONDUCTA PARA FUNCIONARIOS ENCARGADOS DE HACER CUMPLIR LA LEY. ONU. (1979). 
Carolina Cardona Quiceno, Edith Johana Puerto Joya, Karen Margarita Beltrán Peñuela, Ernesto Fajardo Pascagaza, Luis Carlos Cervantes Estrada

promoción, protección y reparación de los derechos humanos con arreglo a la impronta paradigmática mencionada. Además de ello, al apropiarse de los instrumentos internacionales, cada Estado asume el deber de cooperar con las ONG y de permitirles realizar actividades en sus respectivos territorios.

Es importante en este punto resaltar la Sentencia C-067 de 2003 emitida por la Corte Constitucional colombiana, en la que se define el concepto de bloque de constitucionalidad. La suscripción de tratados internacionales por parte de un determinado Estado integra de manera sistemática y articulada tales tratados al ordenamiento jurídico nacional, es decir que por vía del bloque de constitucionalidad, el derecho internacional público pasa a hacer parte de cumplimiento del Estado ${ }^{24}$. Este es un rasgo compartido por los países objeto de comparación gracias a una difusión de este bloque en el constitucionalismo latinoamericano ${ }^{25}$. Se trata en este punto de una inmersión estructural en el ius constitutionale commune latinoamericano.

Como Estados democráticos garantes de los derechos fundamentales, los ordenamientos constitucionales de Chile, Colombia y Brasil reconocen el derecho a la protesta y a la manifestación pacífica. Es así como, en términos de las garantías que tales países brindan en materia de seguridad y de vigilancia, el proceso de investigación ha encontrado que en Colombia esas garantías se plasman en los artículos 2, 6, 20, 22 , 37, 81, 121, 122, 123, 209, 216, 218, 219 y 303 de la Carta Constitucional. Por su parte, en Brasil y en Chile se regula el derecho de reunión, en el entendido de garantizar los derechos individuales y colectivos en una reunión pacifica, sin armas, sin requisito de previa autorización, que al ser convocada se hace necesario el aviso a la autoridad ya establecida. Hay, pues, una constante en el ius constitutionale commune de América Latina que da expresión a un proceso de paulatina democratización. El análisis del modelo de policía en lo que respecta al control de multitudes y a la intervención de la protesta social no puede hacer abstracción de este hecho ${ }^{26}$.

Desde lo constitucional, hay una diferencia sustancial entre los dos países (Chile y Colombia) como la estandarización explícita de la intervención, relacionada con la dinámica del desarrollo histórico que ha determinado el rumbo actual de estos dos Estados. En Chile, se encuentra que los enunciados relativos a la protesta social están

24 Corte Constitucional de Colombia. SENTEnCIA C-067 de 03. (M.P. Marco Gerardo Monroy Cabra; febrero 4 de 2003).

25 Manuel Góngora Mera. La difusión del bloque de constitucionalidad en la jurisprudencia latinoamericana y su potencial en la construcción del lus Constitutionale Commune Latinoamericano. Eds. Armin von Bogdandy, Héctor Fix-Fierro y Mariela Morales Antoniazzi. IUS CONSTITUTIONALE COMMUNE EN AMÉRICA LATINA. RASGOS, POTENCIALIDADES Y DESAFÍOS. (2014). UNAM. Pág. 301-327.

26 Organización de las Naciones Unidas (ONU). PACTO INTERNACIONAL DE DERECHOS CIVILES Y POLÍtICOS. Oficina del Alto Comisionado de las Naciones Unidas. (1976). 
ausentes en el texto y que su objeto aparece denominado con la expresión "el derecho a reunirse pacíficamente". Y en todos los enunciados en los que esta expresión aparece, en el Decreto 1086 del 16 de septiembre de 1983, como complemento a lo relativo al derecho de reunión, el texto resalta las limitaciones, restricciones e imposturas de las que legalmente puede ser objeto. Por ejemplo, las facultades constitucionales que posee el régimen presidencial se imponen al derecho de reunión por declaratoria del Estado de sitio (artículo 13). El posterior análisis del modelo de policía, a partir de la revisión de la estandarización de la intervención, deberá mostrar, en efecto, qué tipo de repercusiones traen consigo estas facultades excepcionales otorgadas al poder ejecutivo. Tales facultades son la "herencia" del periodo dictatorial que vivió la sociedad chilena del 11 de septiembre de 1973 al 11 de marzo de 1990. Es un modelo autoritario de la potestad gubernamental y ello debe ser tenido en cuenta a la hora de evaluar los procedimientos de intervención policial en los escenarios de protesta social.

Por el contrario, Colombia viene de unas negociaciones de paz entre el Gobierno nacional y la guerrilla de las Farc-EP, cuya firma del Acuerdo Final contiene elementos relativos a la problemática que es objeto de estudio. El numeral 2.2.2 establece los criterios que determinan las garantías de las manifestaciones públicas, la protesta ciudadana, la libre expresión y el derecho de libre asociación y reunión en espacios públicos (garantías a la movilización y protesta pacífica, a las manifestaciones ciudadanas, a los derechos humanos, a las regulaciones que controlan el uso de la fuerza por parte de las autoridades públicas, a los acompañamientos del Ministerio Público, etc.)

La lectura de estos criterios contenidos en el Acuerdo Final establece que la situación colombiana, en cuanto a la regulación constitucional, difiere de lo expuesto del caso chileno. Adicionalmente, el sistema jurídico colombiano cuenta con protocolos para el procedimiento de intervención de la protesta (Resolución 1190 de 2018) y con la Ley 1801 del 29 junio de 2016, que reglamenta el Código Nacional de Seguridad y Convivencia Ciudadana (artículo 37), como ejemplos del carácter democrático de la legislación en este país. Es preciso ahondar en las particularidades históricas de Colombia y Chile, a fin de que la reconstrucción analítica del modelo policial en ellos sea esclarecida a la luz de su desarrollo histórico como sistemas sociales y como culturas policiales diferenciadas ${ }^{27}$.

Respecto a las normas de procedimientos, los principios que pautan la racionalidad operativa de las fuerzas policiales están de acuerdo con las exigencias de las garantías que deben procurar en los sistemas jurídicos nacionales en función del ius 
Carolina Cardona Quiceno, Edith Johana Puerto Joya, Karen Margarita Beltrán Peñuela, 19 Ernesto Fajardo Pascagaza, Luis Carlos Cervantes Estrada

constitutionale commune. El análisis comparativo en la siguiente categoría se concentrará en los protocolos que rigen los procedimientos más específicos de la policía antidisturbios.

En el "Modelo para el uso de la fuerza policial de carabineros", las autoridades de Chile establecen prerrogativas de fundamentación que orientan la actuación policial con unos principios explícitos. Como "normas generales relativas al uso de la fuerza", se enuncian como "principios básicos" aquellos que, en caso de ser necesario el uso de la fuerza a la hora de hacer cumplir la ley, deben ser respetados, a saber: 1) principio de legalidad, que regula el uso de la fuerza mediante la aplicación de normas y leyes vigentes; b) principio de necesidad, que exige el uso de la fuerza, especialmente por parte del cuerpo de carabineros, y abstenerse en caso de que no sea necesario; c) principio de proporcionalidad, que mantiene el equilibrio entre la fuerza de la resistencia o agresión efectuada por un ciudadano y la fuerza que debe utilizar el agente de policía para reestablecer el control; d) principio de responsabilidad, en el que se imponen las responsabilidades penales ${ }^{28}$.

En Colombia, hay principios para el desarrollo de operaciones policiales, consignados en la Resolución 02903 de 2017, en cumplimiento de sus funciones. Está en la obligación de respetar los derechos y las garantías constitucionales de los ciudadanos, regulados en la Carta Magna y los tratados internacionales ratificados por este país; teniendo en cuenta los principios básicos para el uso de la fuerza:

- $\quad$ Principio de legalidad: cumplimiento de las facultades otorgadas por la Constitución y la ley.

- $\quad$ Principio de proporcionalidad: está en la obligación de respetar los derechos y garantías de las personas, consagrados en la Constitución política y los tratados internacionales ratificados por el Estado colombiano, sin olvidar los principios básicos para el uso de la fuerza.

- Principio de legalidad: cumplimiento y respeto de las facultades otorgadas por la Constitución y la ley.

- Principio de proporcionalidad: es la relación que debe existir entre el uso de la fuerza y las armas de fuego, y sus consecuencias en términos de afectación de personas y bienes, lo cual debe ser moderado acudiendo siempre a los medios eficaces que ocasionen menor daño. 
- $\quad$ Principio de necesidad: se refiere a la aplicación de medios preventivos y disuasivos previos al despliegue del uso de la fuerza y armas de fuego.

- Principio de racionalidad: es la capacidad de decidir el nivel de fuerza que se debe aplicar, dependiendo del escenario en que se encuentra ${ }^{29}$.

Según el artículo 166 de la Ley 1801 "Código Nacional de Seguridad y Convivencia Ciudadana", el uso de la fuerza es un medio material, necesario, proporcional y racional, empleado por los uniformados de la Policía Nacional como último medio físico para proteger la vida e integridad física, para prevenir, impedir o superar la amenaza o perturbación de la convivencia y la seguridad pública, de conformidad con la ley ${ }^{30}$.

Brasil cuenta con la Ordenanza Interministerial 4.226 de 2010, que "establece lineamientos sobre el uso de la fuerza por agentes de seguridad pública". Considera la necesidad de orientar y establecer los procedimientos en la actuación del uso de la fuerza y las armas de fuego, a fin de reducir gradualmente los índices de letalidad en las acciones en que intervengan los agentes de seguridad pública; también tiene la Ley 13.060 de 2014, "Disciplina el uso de instrumentos de menor potencial ofensivo por parte de agentes de seguridad pública, en todo el territorio nacional". Esta ley es la que regula el uso de instrumentos de menor potencial que causen daño, siempre que el uso no ponga en peligro la integridad física y psicológica del policía, teniendo presentes los principios de legalidad, necesidad, razonabilidad y proporcionalidad; así como saber que el uso de armas de fuego se considera ilegitimo, la capacitación para saber utilizar los instrumentos no letales ${ }^{31}$.

\section{ESTANDARIZACIÓN DE LA INTERVENCIÓN DE LA PROTESTA}

En esta categoría, se tendrán en cuenta los protocolos, manuales o directrices que regulan la intervención de la protesta en cada uno de los países objeto de comparación. Se consideran, como modalidad de la razón procedimental, las lógicas de la intervención desde la situación anterior a la efectuación de la protesta social, pasando por la actuación policial mientras se llevan a cabo los hechos de la protesta, hasta lo que la policía antidisturbios debe hacer cuando la protesta ha terminado. Se hará énfasis

29 Ministerio de Defensa Nacional, supra, nota 6.

30 Ley 1801 de 2016, supra, nota 32.

31 Ministério da Justiça e Segurança Pública. ORdenANZA INTERMINISTERIAL N. ${ }^{\circ} 4.226$, Pub. L. No. 4.226 (2010). 
Carolina Cardona Quiceno, Edith Johana Puerto Joya, Karen Margarita Beltrán Peñuela, 21 Ernesto Fajardo Pascagaza, Luis Carlos Cervantes Estrada

en las directrices que se ponen de manifiesto en la revisión de los protocolos como "guías" utilizadas para la actuación de los cuerpos de policía.

Colombia cuenta con la Resolución 02903 del 23 de junio de 2017 ("Reglamento para el uso de la fuerza y el empleo de armas, municiones, elementos y dispositivos menos letales, por la policía Nacional") y con la Resolución 03002 del 29 de junio de 2017, en la que la Policía Nacional expide el "Manual para el servicio en manifestaciones y control de disturbios". Chile cuenta con varios instrumentos como el "Protocolo para el mantenimiento del orden público" del año 2012, y el modelo llamado "Uso de la fuerza: actualiza instrucciones al respecto"32.

Por su parte, Brasil cuenta con directrices emitidas por cada estado y Policía Militar (Unidad de Choque), de conformidad con las problemáticas que presente cada territorio. Así pues, se tiene presente la norma Ordenanza Interministerial 4.226 de 2010, "Establece lineamientos sobre el uso de la fuerza por agentes de seguridad pública"; la Ley 13.060 de 2014, "Disciplina el uso de instrumentos de menor potencial ofensivo por parte de agentes de seguridad pública, en todo el territorio nacional"; seguido a ello, la norma del estado de Ceará, como referencia para esta investigación, siendo esta "Normas generales de acción de los pelotones de control de disturbios civiles" del 10 de julio de 2020, información obtenida del señor teniente coronel Alkimar Sampaio de Souza (oficial de la Policía Militar del estado de Ceará). Téngase en cuenta que cada país tiene un instrumento o herramienta protocolar que regula los detalles de las intervenciones que la policía puede y debe efectuar frente a las manifestaciones, y en ellos se basa el siguiente análisis comparativo.

\subsection{Antes de la intervención}

En la fase antes, se ha encontrado que las regulaciones protocolares, en términos de su preparación y planeación previa, en Colombia, Chile y Brasil organizan un dispositivo de alistamiento del personal que verifica los datos de localización, en tiempo y espacio, a fin de posicionar tácticamente en el territorio a los cuerpos de policía minimizando riesgos y maximizando la eficacia del control. Esta resolución se articula con la convocatoria de encuentros en los que la policía establece interlocuciones con las dirigencias de la sociedad civil para esclarecer las condiciones cuantitativas de la participación y la predisposición cualitativa de la ciudadanía a cooperar con la labor de los agentes. La prestación del servicio de policía en materia de control de multitudes se debe entonces, en todos los casos, a contar con una previsión acerca de la sinergia institucional, necesaria para maximizar el cumplimiento de las funciones

32 Ministerio del Interior y Seguridad Pública de Chile, supra, nota 33. 
incluyendo en ello los instrumentos que serían necesarios (grupos motorizados, vehículos convencionales o unidades especializadas, etc.). El alistamiento del personal es, pues, un mandato reglamentario.

Durante estas labores de preparación, la policía antidisturbios debe también preparar planes de contingencia que permitan una efectiva reacción ante situaciones inesperadas o que se calculan como improbables. Se trata entonces de un dispositivo de reacción contingente. La ratio fundamental de este dispositivo incluye, además de la eficacia operativa del control, la proyección normativa de una seguridad que debe ser garantizada tanto a las ciudadanías que participan en la protesta como a las que no participan en ella. La elaboración de planes de contingencia podría incluso contar, en el caso colombiano, con la instalación de Puestos de Mando Unificado (PMU) con suficiente tiempo de anticipación, a fin de que el inicio de las manifestaciones de protesta no genere alteraciones del orden público. En Chile, la Central de Comunicaciones de Carabineros (Cenco) se encarga de comunicar, coordinar y apoyar los operativos policiales de "relevancia especial", enlazando los recursos humanos y los materiales tecnológicos de que dispone la institución a fin de responder a eventualidades cuya contingencia desborde los protocolos establecidos. La preparación de esta central se inscribe en la fase previa en vista de su necesaria disposición. En el caso de Brasil, esta coordinación es dirigida por el coordinador de operaciones de cada estado y Unidad de Choque de la Policía Militar.

En estos dos dispositivos, el alistamiento y los planes de contingencia se instalan en un proceso de análisis de información que permite evaluar la situación presente con sus antecedentes y, así, optimizar el aprendizaje de la institución. El análisis de la información debe apoyarse, como en el caso del dispositivo de alistamiento del personal, en interlocuciones con las organizaciones ciudadanas a fin de que la información susceptible de ser recabada pueda integrar los factores que son externos a la ratio institucional de la policía y los organismos de Gobierno nacional y local. Este dispositivo se encuentra presente en los protocolos de Chile y de Colombia, pero no es tan específico en la directriz de Brasil.

Esta labor de aprendizaje maximiza el control de multitudes y se convierte en el punto de articulación y cooperación entre las autoridades de policía y las político-administrativas, configurando así un dispositivo de control jurisdiccional orientado al cumplimiento de los fines u objetivos trazados por la política pública de seguridad ciudadana. En Colombia, los PMU pueden estar integrados tanto por las autoridades de policía que coordinan sus operaciones, como por autoridades gubernamentales que verificarían la legalidad y la legitimidad de las actuaciones. Tanto en Colombia como en Chile, al establecer un dispositivo de control jurisdiccional, la fase previa a 
Carolina Cardona Quiceno, Edith Johana Puerto Joya, Karen Margarita Beltrán Peñuela, 23 Ernesto Fajardo Pascagaza, Luis Carlos Cervantes Estrada

la realización de la protesta (como el alistamiento del personal y el análisis de información) se apoya en interlocuciones previas con las organizaciones ciudadanas que dirigen la protesta, a fin de que la gestión del control jurisdiccional (matizando este punto y retrotrayendo el análisis a las restricciones antes señaladas en el ordenamiento constitucional chileno) sea lo más democrática y participativa posible. En Brasil, no se establece de tal manera, pero sí se encuentra en enlace por el coordinador de operaciones del estado, a propósito de las estructuras y los sistemas subyacentes al modelo de policía, entre Estado centralizado y Estado federado.

La regulación protocolaria del Esmad en Colombia se encuentra accionada por un dispositivo de mediación que es externo y que opera en función de satisfacer las exigencias normativas de la democracia participativa en el escenario de la protesta social y de cara a su regulación: las personas que actúan como "gestoras de convivencia". En Brasil, según la entrevista a profundidad, cuentan con un proceso de negociación para no llegar a utilizar la fuerza y que se pueda dar un buen manejo de crisis, cuando esto sea posible, teniendo el acompañamiento del Ministerio Público. Este equipo de mediación se encuentra ausente, al menos en la fase previa, en las regulaciones protocolarias de Chile. Continuando con Brasil, con base en el documento referido ("Normas generales de acción de los pelotones de control de disturbios civiles" del 10 de julio de 2020), se establece que debe estar preparado un grupo de motorizados para una reacción rápida, y en el capítulo $v$ se define que debe tenerse una instrucción previa al servicio relacionada con las diversas situaciones a las cuales se pueden enfrentar, como el equipamiento del vehículo o las instrucciones desde la técnica de entrenamiento físico y psicológico, ya que para la Policía Militar es importante el entrenamiento y la instrucción diaria, así como la capacitación de las normativas de actuación; lo anterior, teniendo en cuenta la directriz del estado de Ceará.

En Chile, el cop cuenta con un cuadro modelo de uso de la fuerza para carabineros que está dividido en cinco resistencias: cooperación, resistencia pasiva, resistencia activa, agresión activa y agresión activa letal; pueden incrementar o disminuir el uso de la fuerza dependiendo en qué nivel se encuentra la situación, y manejan un protocolo de advertencia de cinco fases en el que se advierte sobre el uso de la fuerza a los manifestantes si no se retiran del lugar de las manifestaciones.

\subsection{Durante la intervención}

Respecto al durante de la intervención, en Colombia en el "Manual para el servicio en manifestaciones y control de disturbios" se definen especificaciones relativas a 
la función del control de multitudes. Entre esas especificidades se habla de unos "parámetros" que las autoridades encargadas de hacer cumplir la ley deben respetar. Llamamos a esto: dispositivo de parametrización. Además de la observación de los principios que rigen al servicio de policía, el Esmad debe esperar a que los gestores de convivencia y el Ministerio Público agoten los mecanismos de mediación. Hay una continuidad del dispositivo de mediación en la fase intermedia de la intervención o control de multitudes, pero ya codificado por parámetros específicos en los que no prima la mediación como condicionamiento, sino que tal mediación entra a ser objeto de limitaciones y habilitaciones de otros medios. Se evalúa como parámetro de la operación policial lo relacionado con la función de garantizar la seguridad ciudadana y el respeto a los derechos de quienes participan y de quienes no participan en las manifestaciones de protesta. Los mandos policiales deberán mantener una comunicación constante sobre todo en caso de reuniones espontáneas con las autoridades político-administrativas a fin de que esa comunicación garantice una coordinación respetuosa de los parámetros legales.

En el caso de Chile, presenta parámetros que habilitan o inhabilitan el uso de la fuerza por parte de las Cop, en los cuales el oficial encargado debe saber tomar las decisiones frente al conflicto y para este fin se adopta un flujo gradual de intervención: diálogo, contener, disuadir, despejar y detener. En el documento referenciado "Manual para el servicio en manifestaciones y control de disturbios", encontramos una distinción a la vez analítica y operativa entre los niveles de resistencia activa (intentos de evasión o resistencia física), agresión activa (intento de agresión contra el carabinero por parte del ciudadano) y agresión activa potencialmente letal (ataque del manifestante contra el carabinero utilizando armamento o instrumentos potencialmente letales). En este caso, el dispositivo de parametrización muestra una diferencia cualitativa con respecto al caso colombiano, ya que no está codificado en función de las garantías democráticas de las que gozaría el ciudadano manifestante, sino en función de una representación de este último como objeto de control y como amenaza potencial. La policía chilena debe procurar reconocer con claridad, con arreglo a la legalidad de las acciones, cuándo es o no lícito hacer uso de la fuerza para detener a un ciudadano manifestante o disolver una manifestación. En Brasil, el pelotón de control de disturbios civiles, los lanzadores y los francotiradores deben estar dispuestos a la reacción, y a cumplir con la misión y los direccionamientos del comandante inmediato.

En Colombia, hay un dispositivo de unificación que determina la racionalidad del procedimiento en busca de una máxima coordinación entre los agentes del operativo policial. Los medios técnicos (tanquetas y vehículos especiales, dotaciones, etc.) están siempre a disposición de los efectivos; sin embargo, al Esmad no le está 
Carolina Cardona Quiceno, Edith Johana Puerto Joya, Karen Margarita Beltrán Peñuela, 25 Ernesto Fajardo Pascagaza, Luis Carlos Cervantes Estrada

permitido efectuar detenciones ni traslados haciendo uso de tales medios, lo cual implica que el dispositivo de unificación posee articulaciones externas que habilitan la intervención de otras unidades de policía encargadas de realizar detenciones y traslados. Debe haber una observación constante de los medios empleados para ejercer las funciones correspondientes procurando que tal ejercicio respete las regulaciones protocolarias; de este modo, el dispositivo de unificación no solo posee articulaciones externas que le aúnan a otras autoridades de policía, sino también a la validación de autoridades constituidas en el orden civil.

En Brasil, el despliegue de este dispositivo una vez se recibe la solicitud (título III, capítulo III) indica que el pelotón de control de disturbios civiles es reunido por los mandos correspondientes para preparar la acción de choque. El documento referido ("Normas generales de acción de los pelotones de control de disturbios civiles" del 10 de julio de 2020) puntualiza las relaciones directas entre el comandante del pelotón y el sargento auxiliar, a fin de que estos puedan coordinar instrucciones en cumplimiento de la misión y los objetivos propuestos, y en las que cada miembro del pelotón asuma una función diferenciada y especificada, sin olvidar las responsabilidades que debe asumir cada miembro de la Unidad de Choque; el comandante dará la orden para desembarcar, su actuación es cuando tengan visibilidad del terreno oponente, con una distancia prudente, actúa con la norma, sin tener en cuenta asuntos políticos y el empleo de los medios logísticos.

En la fase intermedia, el caso colombiano muestra el despliegue de un dispositivo de distribución espacial que establece distinciones operativas entre formaciones de respaldo y consolidación de zonas menos conflictivas, entre lugares de concentración y puntos estratégicos; esto con base en un criterio estratégico general que se reparte entre lo visible y lo no visible, y que permite a los agentes de policía seguir de cerca los acontecimientos y dar una respuesta eficaz y oportuna a la situación cuando esta lo requiera. Todas las labores de mediación y acompañamiento deben coordinar sus acciones y procedimientos de acuerdo con las exigencias operativas de este dispositivo de distribución espacial. El Esmad debe coordinar con la gestión de convivencia, a fin de que en su colaboración mutua se pueda resguardar la integridad de las personas que transitan, habitan o trabajan cerca de los lugares de concentración; los cuerpos policiales no solo están habilitados para resguardar a la ciudadanía, sino también para disuadir a esta de asumir comportamientos que puedan degenerar en expresiones de vandalismo. Este dispositivo puntualiza nuevamente las articulaciones entre las autoridades policiales, la gestión civil y el acompañamiento ministerial. En Chile, el despliegue de este dispositivo inaugura la etapa de contención de las manifestaciones ilícitas y sin autorización, porque la parametrización propiamente 
policial supone un trazado territorial que delimita geográficamente el desplazamiento lícito o ilícito de los manifestantes.

En Brasil, se contempla el rol de los escuderos que consiste en ubicarse en posición defensiva de tal modo que protejan al pelotón de lanzamiento, que se ubica en un lugar intermedio entre retaguardia y defensa frontal; de hecho, se considera que son los escuderos las formaciones que, por su ubicación, definen el éxito o el fracaso de la operación. El documento trata sobre la inscripción de los vehículos en este dispositivo de distribución espacial, ya que estos cumplen una función doble: custodiar y transportar a los efectivos de policía que operan sin vehículo y despejar el terreno entrando al choque directo con las multitudes; la dirección de los vehículos se organiza en torno a un itinerario estratégicamente prefigurado y con arreglo a unos tiempos definidos (artículos 27 y 28). La diferencia cualitativa entre la regulación protocolaria de la fase intermedia en Brasil recae en la autoorganización del cuerpo policial y no en determinaciones estratégicas de posicionamiento frente a la manifestación.

Otro dispositivo es el de registro. En Colombia, el Esmad está integrado por agentes de policía y por instrumentos técnicos que facilitan obtener un registro audiovisual que pueda servir como material probatorio o evidencia física susceptible de ser utilizada en posteriores investigaciones administrativas, disciplinarias o penales. El dispositivo de registro actúa también como una serie de prácticas protocolizadas que permiten a los agentes de policía registrar los datos personales de los ciudadanos que resulten detenidos o heridos durante las manifestaciones, a fin de que obtengan representación jurídica o atención médica y de que sus familias sean debidamente notificadas sobre los hechos ocurridos.

En Chile, también existen acciones de registro, pero no se especifica el proceder de la policía con respecto a la atención médica o a la notificación familiar, y se prohíben, explícitamente, las detenciones masivas y arbitrarias. Así mismo, el dispositivo de distribución espacial tiene conexidad con el dispositivo de parametrización. El Esmad debe permitir que los medios de comunicación tengan una acreditación como comunicadores sociales profesionales y que registren en sus medios particulares los acontecimientos ocurridos durante las manifestaciones de protesta social, garantizando con ello el derecho de las ciudadanías a la libre expresión e información.

En Brasil, el comandante del pelotón debe asumir, en lo que respecta a la fase intermedia, responsabilidades como la inspección de los materiales utilizados, dirigir el comportamiento de los agentes subordinados ante los manifestantes, la unidad operativa del pelotón, supervisar directamente la preparación de las documentaciones exigidas por la ley, así como la comunicación y cooperación de los miembros de la Policía Militar. El caso brasileño presenta una diferencia cualitativa 
Carolina Cardona Quiceno, Edith Johana Puerto Joya, Karen Margarita Beltrán Peñuela, 27 Ernesto Fajardo Pascagaza, Luis Carlos Cervantes Estrada

importante en lo que se refiere al dispositivo de registro, porque este ya no opera directamente sobre el control de las multitudes, sino sobre la supervisión interna de las operaciones policiales.

En Colombia, se hace visible un dispositivo de disolución que se activa una vez la situación corra el riesgo de salirse de control y provocar alteraciones del orden público, de convivencia y seguridad. Este dispositivo, como ultima ratio, se despliega como habilitación de los cuerpos de policía para disolver la manifestación a fin de que puedan ser reestablecidas las condiciones sociales en las que es posible para las ciudadanías gozar de sus derechos. En caso de ser requerida la disolución de la protesta, los mandos de la policía deberán notificar tanto a las autoridades político-administrativas, como a las personas organizadoras de la protesta. Por su parte, la policía antidisturbios de Chile efectúa un progresivo despliegue del dispositivo de disolución diferenciando entre una etapa previa de disuasión, una etapa intermedia de despeje, una etapa de disolución y una etapa final de detención. La primera es advertida a los manifestantes como una posibilidad suscitada por las infracciones a la ley y por el desacato a las instrucciones policiales, lo cual amerita un uso proporcionado y controlado de la fuerza; la segunda etapa procura despejar el territorio evitando el uso de la fuerza (que es siempre ultima ratio), haciendo uso de altavoces y dando prioridad a la evacuación de adultos mayores, mujeres embarazadas y niños; la tercera etapa procede ya a la disolución de la protesta retirando del lugar a todos los manifestantes y procurando abrir los espacios necesarios para ello, y recurriendo, en caso de ser necesario, al uso de balizas, sirenas, voliciones de aproximación, el uso del pitón, de vehículos lanza aguas o de vehículos tácticos de reacción (incluso el uso combinado de estos dos últimos); finalmente, en la cuarta etapa los agentes de policía proceden a capturar a los manifestantes que hayan cometido delitos o que hayan incurrido en contravenciones y a remitir en estos casos la información debida a los tribunales correspondientes. En Brasil, los diferentes miembros del grupo cuentan con unas articulaciones en torno a las responsabilidades del comandante del pelotón de control de disturbios civiles, señalando la supervisión de las municiones y el material químico que se utiliza a la hora de disolver la protesta, la actitud y la preparación de sus subordinados, y la coordinación del pelotón mencionado con el pelotón de conmoción.

\subsection{Después de la intervención}

En lo que respecta al después de la intervención de la protesta social, el análisis comienza por señalar que en los documentos referenciados al inicio de esta categoría 
los casos de Brasil y Chile no establecen taxativamente lo que respecta a los reportes de evaluación. En Colombia, sí se asume la elaboración de esos reportes. Brasil y Chile no cuentan con un manual específico que indique lo que debe hacerse y describirse, etapa por etapa, en el proceso de intervención bajo los términos de una razón evaluativa. En las entrevistas a profundidad, se identificaron aspectos como que al finalizar las manifestaciones los grupos antidisturbios presentan dicho informe dando a conocer todo lo referente a la intervención, heridos, técnicas utilizadas y demás aspectos relevantes; esto ocurre en los tres países objeto de estudio.

En Colombia, la regulación protocolaria establece que es necesario mantener la presencia de la policía hasta que puedan ser garantizadas las condiciones de normalidad en la movilidad, la seguridad y la convivencia. Llamamos a esto: dispositivo de normalización. El comandante de la unidad debe informar al PMU lo ocurrido antes, durante y después de las manifestaciones y el cuerpo de policía procederá a "desinstalar los dispositivos policiales" descritos a lo largo de estos análisis, procurando que, en caso de ser necesario, haya un retorno de otras fuerzas policiales que prestan apoyo. Una vez hayan sido desinstalados tales dispositivos, los comandantes de la región metropolitana y el departamento de policía deben coordinar el retorno del personal uniformado.

Otro dispositivo presente en la fase última de la intervención podría denominarse dispositivo de evaluación, pues consiste en hacer la revisión de los hechos ocurridos de acuerdo con los parámetros determinados por las leyes del Estado y por los protocolos de actuación. En esta evaluación, deben ser destacados los aciertos, los desaciertos y las recomendaciones a que haya lugar, con el propósito de optimizar la prestación de los servicios y procedimientos policiales. La magnitud de los acontecimientos y de afectación de estos sobre el orden público distribuyen, en función del dispositivo jurisdiccional, los mandos responsables por esas afectaciones (criterio de mando y dirección, artículo 16). Los comandantes de las jurisdicciones afectadas deben evaluar el desempeño policial de acuerdo con las garantías prestadas al derecho de reunión y manifestación pública (presunción a favor de la no estigmatización, artículo 18); sin embargo, en caso de haber detenciones de ciudadanos que hayan incurrido en delitos o en contravenciones, las comandancias jurisdiccionales deben coordinar con la Dirección de Seguridad Ciudadana y, a través de ella, con la Fiscalía General de la Nación, la identificación, individualización y judicialización de quienes hayan atentado contra la seguridad y la convivencia de sus conciudadanos. 
Carolina Cardona Quiceno, Edith Johana Puerto Joya, Karen Margarita Beltrán Peñuela, 29 Ernesto Fajardo Pascagaza, Luis Carlos Cervantes Estrada

\section{PERCEPCIÓN CIUdAdANA SOBRE LA INTERVENCIÓN DE LA PROTESTA}

Según Pérez, Silva y Cano ${ }^{33}$ sobre el uso de la fuerza en América Latina, el desempeño general de la policía no es percibido de manera positiva; el abuso de la fuerza policial es lo suficientemente alto como las desconfianzas ciudadanas que afectan de forma directa a las condiciones socioculturales de la seguridad. El número de personas muertas a manos de la fuerza pública es también visto con preocupación. El control de multitudes en escenarios de protesta social adquiere unos matices particulares en cada país por las problemáticas sociales y por el despliegue del modelo de policía, por la tradición cultural que permea a ese modelo y por la cultura política que caracteriza a las ciudadanías de cada país: en Colombia, las movilizaciones agrarias y estudiantiles; en Chile, los estudiantes, los trabajadores y la comunidad universitaria; y en Brasil, los colectivos antirracistas, entre otros, han denunciado actitudes delictivas por parte de la policía antidisturbios. Pareciera ser que, de cara a la percepción ciudadana, la intervención de la protesta social en estos tres países se caracteriza por la inexistencia de instancias reales de diálogo y canalización política de los conflictos sociales. El uso de la fuerza suele preceder a las mediaciones dialógicas y, en esa medida, la inaplicabilidad de los protocolos se convierte en una constante que verifica una inadecuación estructural entre los medios y los fines de la intervención policial ${ }^{34}$.

Para Maía, Tordini y Pol35, hay otros factores de inadecuación estructural, según las percepciones ciudadanas, en los que la imposibilidad de un diálogo efectivo capaz de evitar la confrontación violenta entre los miembros de policía y los manifestantes reside en la poca o nula presencia de las autoridades públicas con poder de decisión en los lugares de manifestación. La percepción ciudadana consiste en la denuncia de un uso indiscriminado de armas menos letales, de letalidad reducida (gases, balas de goma, etc.). Como efecto de una saturación policial y encapsulamiento, se denuncian también las presiones psicológicas que la policía antidisturbios, en su despliegue táctico, produce sobre los manifestantes al ocupar el territorio ${ }^{36}$.

33

34 Bergmann et al., supra, nota 7.

35 Camila Maia, Ximena Tordini y Luciana Pol (coords.). Los estados LatinOamericANOS FRENTE A LA PROTESTA SOCIAL. CENTRO DE ESTUDIOS LEGALES Y SOCIALES. (2016). Disponible en https://www.cels.org.ar/web/wp-content/uploads/2017/01/Protesta_ social_regional_web-1.pdf

$36 \mathrm{Ibid}$. 
La percepción de la comunidad en Chile, según la encuesta Cadem para el 4 de diciembre de 2019, es que solo 35 \% de los chilenos aprueba la función realizada por los carabineros; es el nivel más bajo desde que empezó la medición en septiembre de 2015, cuando esta institución destacaba muy por encima de otros organismos estatales con una aceptación del $72 \%{ }^{37}$.

En Brasil, en una investigación realizada en 2014 sobre la policía de Río de Janeiro, el 64\% de los agentes entrevistados declararon no haber recibido entrenamiento adecuado para actuar en manifestaciones. Para los casos ocurridos en Brasil revisados en el informe de 2015 de la Comisión Interamericana de Derechos Humanos ( $\mathrm{CIDH})$, sobre el uso de la fuerza se establece que con el alto índice de letalidad en las actuaciones policiales (como en Río de Janeiro), la Corte determina que se deben decretar unas políticas para la reducción de la letalidad y la violencia policial, de manera que deben dar cumplimiento a la creación de la Ley 13.060 de 2014, "Ley Federal de disciplina y uso de los instrumentos de menor potencial ofensivo por los agentes de seguridad pública en todo el territorio nacional", con el fin de ajustar el uso de armas de fuego y de armas menos letales en las protestas en pro de la garantía de normativa internacional ${ }^{38}$.

Se han denunciado también, en Chile, Colombia y Brasil, la ejecución de detenciones masivas, arbitrarias y violentas como una táctica de amedrentamiento y represión policial contra la movilización ciudadana. El uso de la fuerza presenta excesos que mueven la percepción de las ciudadanías a un rechazo de la actuación policial, considerando que dicha actuación no protege ni garantiza las libertades constitucionales, por lo cual se denuncia la efectuación de detenciones decididas bajo criterios discriminatorios. A su vez, se denuncian irregularidades procedimentales en las detenciones al no remitir, debidamente, los casos a las autoridades judiciales (evidencias fraguadas, montajes testimoniales, provocaciones no informadas ni esclarecidas).

En Chile, investigadores del Instituto Nacional de Derechos Humanos (INDH) sostienen que a pesar de que los protocolos regulan la actuación de carabineros ordenando poner en libertad a los menores de edad sin exigir la presencia de un acudiente, los agentes de policía les retienen exigiendo dicha condición. En Colombia, la figura de la retención por protección codificada en el Código Nacional de Policía habilita la detención de personas con alteraciones emocionales prescindiendo de orden judicial, y esa norma fue utilizada en varias ocasiones para la detención de jóvenes durante

37 Cadem. Encuesta Plaza Pública N. 348. (2019). Disponible en https://www.cadem.cl/ encuestas/estudio-no-307-29-de-noviembre-2/

38 Comisión Interamericana de Derechos Humanos (CIDH). Capítulo IV. Panorama de la situación de derechos humanos en el hemisferio: uso de la fuerza. INFORME ANUAL 2015. Ed. CIDH. (2015). 
Carolina Cardona Quiceno, Edith Johana Puerto Joya, Karen Margarita Beltrán Peñuela, 31 Ernesto Fajardo Pascagaza, Luis Carlos Cervantes Estrada

las protestas del 1 de mayo de 2013. La inadecuación estructural en estos casos es más que evidente ${ }^{39}$.

Existen otros temas denunciados como los ataques a la libertad de expresión que reprimen las actuaciones de la prensa no oficial, y la formación, capacitación y entrenamiento inadecuado del personal uniformado que cultiva en dicho personal imaginarios de odio. En Brasil y en Venezuela, cerca de 64 \% de los agentes entrevistados en un estudio desarrollado en 2014 declaró no haber recibido entrenamiento adecuado para actuar durante las manifestaciones. Otros personas y grupos denuncian la presencia de uniformados encubiertos (los "P2" en Brasil, por ejemplo) en medio de las multitudes actuando como instigadores y saboteadores de la protesta, cuyos actos terminan "justificando" la represión contra los ciudadanos; se denuncia en todos los casos un nivel de impunidad que impide que las infracciones cometidas por los agentes de policía sean sancionadas de manera ejemplar (lo que, a la larga, estimula su comisión). Se denuncia la inexistencia de criterios claros sobre la dispersión de las protestas y para las detenciones y requisas, lo cual es muy importante a la hora de evaluar el desempeño de la policía antidisturbios en los casos de Brasil. En Chile y en Colombia, tales criterios son observados con más claridad, pero denunciados por su incumplimiento ${ }^{40}$.

\section{SANCIONES A LA Policía}

Las denuncias contra el abuso de la fuerza por parte de la policía antidisturbios se reflejan en denuncias, sentencias y referentes de medios de comunicación nacionales e internacionales, entre otros. La movilización ciudadana se ha intensificado por razones diversas en el marco de cada Estado objeto de estudio (Colombia, Chile y Brasil). Ha habido algunas sanciones significativas que generan cuestionamientos y replanteamientos parciales de los procedimientos policiales.

En Colombia, la muerte del joven Nicolás Neira en 2005 provocó la sanción y destitución por diez años del capitán Julio César Torrijos. La particularidad de este caso muestra una situación en la que la coacción física de los agentes de policía fue excesiva y provocó la muerte del menor de edad ${ }^{41}$. Casi diez años más tarde, durante el paro agrario de 2013 en Boyacá, una de las muchas denuncias interpuestas fue

39 Maía et al., supra, nota 40.

40 Ibid.

41 El Espectador. MUERTE DE NICOLÁS NEIRA MOTIVA DESTITUCIÓN DE AGENTES DEL ESMAD. 4 de enero de 2010. Disponible en https://www.elespectador.com/noticias/judicial/ muerte-de-nicolas-neira-motiva-destitucion-de-agentes-del-esmad/ 
de miembros del Esmad que lesionaron a un ciudadano que estaba en el lugar. La demanda de reparación directa a la Policía Nacional prosperó, pues se probó que este ciudadano sufrió lesiones que generaron una incapacidad médico-legal de ochenta días y una deformidad física que afectó su pie derecho de manera permanente; quedó claro que se configuraron fallas en el servicio por mal uso de la fuerza, pues fue desproporcionada ${ }^{42}$.

En Chile, ha sido mucho más difícil individualizar y llegar a sanciones directas contra los uniformados. En cuanto a los abusos denunciados, la intensidad chilena es alta como la colombiana, pero resulta difícil para la ciudadanía adelantar procesos penales. En el informe de 2013 sobre la situación de derechos humanos en Chile, teniendo en cuenta la constante presencia de las organizaciones protectoras de derechos humanos, ser aborda uno de los casos presentados en Antofagasta, Asyen y en los territorios de "conflicto mapuche". Se presentaron denuncias de violencia por parte de la Policía de Carabineros en las marchas del movimiento estudiantil, en el marco de los acontecimientos de "abusos sexuales" que han estado más alejados de un control y de una visibilidad ciudadana que facilite su judicialización efectiva: las denuncias no llegan a los tribunales ${ }^{43}$. Otro de los casos en Chile por el mal uso de la fuerza fue con el estudiante de la Universidad Católica de Chile Rodrigo Avilés, de 28 años, quien quedó en coma luego del ataque que sufrió por parte de las entonces fuerzas especiales de carabineros encargadas de dispersar a los manifestantes el 21 de mayo de 2015, cuando fue golpeado en su cabeza por un chorro de agua que lanzan las tanquetas. Este caso desató una discusión pública sobre el límite del uso de la fuerza, según el medio de comunicación Tele 13. Dado que no se evidenció por otras fuentes el resultado de este caso, el funcionario implicado en ello fue alejado de la institución y durante la investigación mantuvo su versión de que nunca vio a Rodrigo cuando operaba el carro lanza aguas.

La investigación de la Fiscalía se formalizó contra un ex carabinero que manejaba el chorro al momento del ataque. Ahora el exfuncionario es acusado por el Instituto Nacional de Derechos Humanos (INDH) como autor de los delitos de homicidio frustrado con resultado de lesiones graves y solicita 15 años de cárcel. El Ministerio Público, en tanto, lo acusa de

42 Secretaría General del Tribunal Administrativo de Boyacá. POR EL USO EXCESIVO DE LA FUERZA PÚBLICA EN EL PARO NACIONAL AGRARIO DEL AÑo 2013, CONDENAN A LA POLICÍA NACIONAL AL PAGO DE PERJUICIOS. Noviembre 30 de 2017.

43 Instituto Nacional de Derechos Humanos. INFORME ANUAL SITUACIÓN DE LOS DERECHOS HUMANOS EN CHILE. Instituto Nacional de Derechos Humanos. (2013). 
Carolina Cardona Quiceno, Edith Johana Puerto Joya, Karen Margarita Beltrán Peñuela, 33 Ernesto Fajardo Pascagaza, Luis Carlos Cervantes Estrada

lesiones graves, solicitando una pena de 540 días. La familia Avilés además acusa por el delito de violencia innecesaria, requiriendo una pena de 10 años".44

En Brasil, los certámenes deportivos que tuvieron lugar en 2013, 2014 y 2016, y las movilizaciones y protestas que se suscitaron en Rio de Janeiro, presentaron denuncias contra la Policía Militar al incrementarse abusos de la fuerza. Un caso registrado fue en 2015 en el estado de São Paulo por protestas contra las políticas de cambios educativos, en las que hubo persecución y violencia contra los estudiantes de la protesta. La CIDH dice que el aspecto psicológico se vio afectado en razón a la represión ocasionada. Las personas que denunciaron los abusos son camarógrafos, periodistas, extranjeros, etc. Sin embargo, en este país las denuncias tienen todavía más dificultades que en el caso chileno para prosperar; en este sentido, puede decirse que tiende a acentuarse la impunidad ${ }^{45}$.

\section{DISCUSIÓN DE RESULTADOS}

Esta investigación describe la estructura de los grupos antidisturbios de Colombia, Chile y Brasil, y así mismo, se analiza la normativa nacional e internacional relacionada con el control que ejerce la policía en la protesta social; de igual manera, localiza los instrumentos (protocolos, manuales y directrices) de intervención. Teniendo en cuenta el tema de estudio comparativo de los grupos antidisturbios en el control de la protesta social en los países mencionados, de conformidad con la doctrina, la normatividad nacional e internacional, la normativa interna, sus cartas constitucionales y las entrevistas a profundidad realizadas a los miembros de la policía de los países objeto de estudio, se concluyen aspectos importantes y diferenciales de los distintos grupos antidisturbios, así como algunas similitudes y diferencias que permiten ser referencia a nivel internacional.

En el análisis de las dinámicas por fases en la intervención, es importante tener en cuenta la organización y la estructura de estos grupos antidisturbios en Colombia, Chile y Brasil. Se observa que Colombia es un Estado social de derecho organizado en república unitaria, Chile es un Estado de derecho de tipo unitario y Brasil es un Estado democrático de derecho, siendo una república federal. Estos grupos de

\footnotetext{
44 Tele 13. COMIENZA PREPARACIÓN DE JUICIO ORAL CONTRA EX CARABINERO QUE HIRIÓ A RODRIGO AVILÉS. 3 de enero de 2019. Disponible en https://www.t13.cl/noticia/nacional/comienza-preparacion-juicio-oral-ex-carabinero-hirio-rodrigo-aviles
} 
choque tienen una estructura orgánica que se diferencia: en Colombia, forma parte de la Dirección General de la Policía Nacional, Subdirección General, Dirección de Seguridad Ciudadana (Disec), Comandos Unidades Operativas Especiales, al cual pertenece la Unidad Nacional Antidisturbios (Unadi); en Chile, la estructura orgánica inicia con una Dirección General de Carabineros, seguida de una subdirección, la Dirección Nacional del Orden de Seguridad, la Jefatura de Zona Metropolitana y la Zona Control del Orden Público e Intervención, luego de la restructuración queda con una división en la Metropolitana de Zona Este (28 Comisaria) y Zona Oeste (40 Comisaria); y en Brasil, la Policía Militar hace parte de la Secretaría de Seguridad Pública desde una vinculación y no como dependencia; cada director de la Policía Militar tiene competencia y autonomía en su estado, y subordinado a ello se cuenta con el Comando de Policía de Choque, del cual se derivan unos batallones que son diferentes según las problemáticas o necesidades que presente cada estado. Se debe dejar claro que en todos los Estados el organigrama puede ser diferente en el entendido de que el director tiene autonomía con su policía; de igual manera, la organización de las problemáticas que se presenten.

La normativa internacional, nacional e interna que rige la intervención para Colombia, Chile y Brasil se encuentra vigente, en algunos casos con sus respectivas modificaciones, lo que permite un avance institucional en la policía de cada país. En el ámbito internacional, se infiere que los tres países forman parte de dichas normas al ser ratificadas por los Estados miembros en las organizaciones internacionales, compartiendo obligaciones y compromisos relacionados con el cumplimiento de normas de los derechos humanos. En Colombia, se garantiza el derecho a la reunión o manifestación pública y de manera expresa solo la Constitución Política y la Ley hacen excepciones a este derecho; en Chile quienes organizan la manifestación pública deberán informar dos días según el Decreto 1086 del 16 de septiembre de 1983 "Reuniones públicas"; y en Brasil se establece que pueden reunirse pacíficamente sin armas, con previo aviso a la autoridad competente, garantizando los derechos y deberes individuales y colectivos.

Dentro de la normativa interna referente al uso de la fuerza, creados en necesidad y garantía de los derechos humanos, se establecen protocolos, directrices, instructivos y resoluciones según sea el caso. En Colombia, se cuenta con la Resolución 02903 del 23 de junio de 2017 "Reglamento para el uso de la fuerza y el empleo de armas, municiones, elementos y dispositivos menos letales, por la Policía Nacional" y con la Resolución 1190 del 3 de agosto de 2018 "Protocolo para la coordinación de las acciones de respeto y garantía a la protesta pacífica como un ejercicio legítimo de los derechos de reunión, manifestación pública y pacífica, libertad de asociación, libre 
Carolina Cardona Quiceno, Edith Johana Puerto Joya, Karen Margarita Beltrán Peñuela, 35 Ernesto Fajardo Pascagaza, Luis Carlos Cervantes Estrada

circulación, libre expresión, libertad de conciencia, a la oposición y a la participación, inclusive de quienes no participan en la protesta pacífica". En Chile, está la Circular 1832 llamada "Uso de la fuerza: actualiza instrucciones al respecto al 01 de marzo de 2019. Brasil cuenta con la Ordenanza Interministerial 4.226 de 2010, "Establece lineamientos sobre el uso de la fuerza por agentes de seguridad pública", así como con la Ley 13.060 de 2014, "Disciplina el uso de instrumentos de menor potencial ofensivo por parte de agentes de seguridad pública, en todo el territorio nacional".

Estos países cuentan con manuales de procedimiento en sus fases antes, durante y después de las protestas. En Colombia, se estableció la Resolución 03002 del 29 de junio 2017, "Manual para el servicio en manifestaciones y control de disturbios"; Chile tiene la Orden General 2635, "Protocolo para el mantenimiento del orden público" del año 2012, y el "Manual de operaciones para el control del orden público"; finalmente, en Brasil como país federal cada Policía Militar (Unidad de Choque) reglamenta sus propias directrices según el estado, las necesidades y las problemáticas. Como ejemplo, se cuenta con la Directriz del Estado de Ceará denominada "Normas generales de acción de los pelotones de control de disturbios civiles" del 10 de julio de 2020, expedida por el primer teniente QOPM ${ }^{46}$ Meireles Soares de Alencar. Según lo anterior, se logra evidenciar una gran diferencia en Brasil, pues su protocolo de actuación va enlazado a las problemáticas que se presenten en cada Estado, algo muy diferente de lo que sucede en Colombia y Chile, donde los protocolos y las normativas son establecidas en protección del derecho a la protesta, el actuar de la policía en el uso de la fuerza y el restablecimiento de derechos.

Teniendo presente el informe anual de la CIDH del año 2018, el acápite de la protesta social hace referencia al uso excesivo de la fuerza por parte de los grupos antidisturbios en los países objeto de estudio. En primer lugar, el Examen Periódico Universal de organizaciones sociales y de derechos humanos informó la constancia en los últimos años de un uso excesivo de la fuerza en el ámbito de protestas sociales en Colombia. Según el Informe del Alto Comisionado de las Naciones Unidas para los Derechos Humanos, publicado en marzo de 2018, catorce personas fueron asesinadas en las protestas sociales desarrolladas en 2017, siendo una constante la ocurrencia de estos hechos para este contexto. En referencia a Chile, reciben información acerca de un uso excesivo de la fuerza por parte de elementos de la Policía de Chile con el objetivo de dispersar a manifestantes, de manera que la CIDH "establece que la protesta social es una herramienta fundamental para la labor de defensa de los derechos humanos, y esencial para la expresión crítica política y social de las actividades de las autoridades". En Brasil, la CIDH recibe denuncias a limitaciones en el

46 Cuadro de Oficiales de la Policía Militar. 
marco de la protesta social y la defensa de los derechos humanos; uno de los hechos más problemáticos fue en el año 2013 cuando se maximizó la restricción del ejercicio de la protesta y la manifestación social (y por ende, de los derechos humanos). Es el Estado el principal garante de la protección y goce de los derechos humanos, y por lo tanto debe intervenir en el momento en que se vean vulnerados ${ }^{47}$.

Las entrevistas realizadas aportan recomendaciones y opiniones en referencia a la propuesta institucional desde la visión de la experiencia, la experticia y el conocimiento. En ese orden de ideas, los entrevistados del Esmad manifestaron su interés por la propuesta institucional de innovación, ya que podría servir como blindaje en el ámbito jurídico en un paso que se da para evitar el uso de la fuerza, y entre otras cosas afianza la legitimidad, la aceptación, con transparencia y profesionalismo en el actuar; de igual manera, se recomienda que se realice una propuesta a los alcaldes a que, por iniciativa propia, creen equipos de gestores de convivencia que lleven a cabo la mediación, con el fin de que la carga no sea solo del Esmad, sino que este forme parte de una mesa de diálogo y comunicación con los manifestantes.

Por su parte, el entrevistado sargento de carabineros de Chile está de acuerdo con la propuesta en el entendido de que la mediación se lleve a cabo solo en aquellos casos en los que es posible el diálogo, es decir, cuando la protesta no esté en completa alteración de orden público, pues tal situación implica la aplicación directa del uso de la fuerza. Por último, el señor oficial de Brasil cree en la propuesta, ya que permite una policía capacitada y cercana a la comunidad; manifiesta que en su país existe una figura similar a la mediación denominada negociación, que es realizada por un oficial con el fin de evitar riesgos y apoyar en el manejo de disturbios, lo cual ha tenido una muy buena acogida por parte de los ciudadanos y la Policía Militar.

\section{CONCLUSIONES}

Las estructuras de organización de los grupos antidisturbios son diferentes para los países de Colombia, Chile y Brasil no solo por su forma de Estado, sino también por las problemáticas que se presentan en cada uno.

Colombia, Chile y Brasil, en acatamiento de las disposiciones internacionales sobre uso de la fuerza, emiten sus manuales, reglamentos, flujogramas de procedimiento y demás normas relacionadas con la atención de multitudes y disturbios.

47 Organización de los Estados Americanos (OEA). INFORME ANUAL 2019 DE LA COMISIÓN INTERAMERICANA DE DERECHOS HUMANOS. CIDH. (2019). Disponible en http://www.oas. org/es/cidh/docs/anual/2019/indice.asp 
Carolina Cardona Quiceno, Edith Johana Puerto Joya, Karen Margarita Beltrán Peñuela, 37 Ernesto Fajardo Pascagaza, Luis Carlos Cervantes Estrada

En lo que respecta a Colombia y Chile, el procedimiento a seguir en la atención de disturbios y multitudes es mejor organizado, teniendo en cuenta que se indica el proceder por fases de una manera taxativa y clara. Caso contrario sucede en Brasil donde la directriz que emite cada estado, de conformidad con la normativa constitucional, no desarrolla un procedimiento completo en sus diferentes fases, pues no se puede olvidar que estas son emitidas teniendo en cuenta las problemáticas y necesidades individuales de cada estado.

En Brasil, los comandantes de los batallones de choque tienen autonomía para dictar normas sobre el direccionamiento y la actuación de la Policía Militar, las cuales regirán en el estado que las emita. Como ejemplo, está la Directriz del estado de Ceará, denominada "Normas generales de acción de los pelotones de control de disturbios civiles" del 10 de julio de 2020, que fue expedida por el primer teniente QopM Meireles Soares de Alencar; caso contrario se presenta en Colombia y Chile, donde las normas son dictadas por los ministerios (Ministerio de Defensa para Colombia y Ministerio del Interior y Seguridad Pública para Chile).

El flujograma de procesos y el "Manual para el servicio en manifestaciones y control de disturbios para la Policía Nacional" establecen las etapas (antes, durante y después) que se deben seguir para la intervención de disturbios y manifestaciones. En la propuesta institucional, se establece que en la fase "antes" actual, cuando se considere necesario, intervengan los gestores de convivencia o quien haga sus veces, así como el Ministerio Público, con el fin de restablecer la seguridad y la convivencia, y para que no sea necesario el empleo de la fuerza por parte del grupo antidisturbios. La propuesta pretende capacitar al personal del Esmad con el propósito de que ellos sean quienes asuman el rol de mediación y comunicación con los manifestantes, puesto que actualmente (sin que se encuentre establecido dentro la normativa interna de este grupo específico) en ocasiones la policía antidisturbios hace la mediación evitando la alteración del orden público y el uso de la fuerza, toda vez que es utilizada una herramienta de diálogo con los líderes de la manifestación. Esta propuesta busca que se incorpore el accionar en el flujograma y el manual respectivo para la atención de manifestaciones, pretendiendo que la Policía Nacional cada vez está más capacitada en el rol de la mediación en las diferentes especialidades; esto en su función preventiva, generando así una comunicación previa entre el Esmad y los manifestantes.

Se propone una prueba piloto para capacitar al $5 \%$ del personal del Esmad, que integra dos partes: capacitación y participación. En la primera parte, se pretende que el personal de los grupos antidisturbios reciba formación frente a la mediación; la segunda parte consta de componer una mesa de diálogo entre el Ministerio Público, la Policía Nacional, los gestores de convivencia y los posibles manifestantes, produciendo 
un trabajo mancomunado entre los diferentes integrantes que permita llegar a un acuerdo y así evitar el uso de la fuerza y los disturbios en las manifestaciones.

De acuerdo con las entrevistas realizadas a miembros de los grupos antidisturbios de las instituciones policiales de Colombia, Chile y Brasil, la propuesta institucional es innovadora y de gran interés para la Policía Nacional, ya que fomenta el diálogo y la capacitación en mediación, con el fin de dirimir conflictos, evitar escalonamientos a delitos y el uso de la fuerza. De tal modo, el Esmad, además de ser un grupo de choque, tendrá también una figura de diálogo antes de entrar al proceso de intervención, lo cual fortalecerá el servicio de policía.

\section{REFERENCIAS}

Adrian Bergmann, Andrés Ruiz Ojeda, Carlos Silva Forné, Keymer Ávila, et al. MonITOR DEL USO de la Fuerza letal en América latina: un estudio comparativo de Brasil, Colombia, El Salvador, MÉxico y VenezUela. Fundación Ideas para la Paz; IIJ-unam. (2019).

Asamblea Nacional Constituyente. Constitución Política de LA RepúblicA de Colombia. Legis. (1991).

Asel Mercado Maldonado y Guillermo González Velásquez. La teoría del conflicto en la sociedad contemporánea. EsPacios PúBlıcos 21. Febrero de 2008. Pág. 196-221. Disponible en https:// www.redalyc.org/pdf/676/67602111.pdf

Benjamín Tejerina Montaña. Las teorías sociológicas del conflicto social. Algunas dimensiones analíticas a partir de K. Marxy G. Simmel. REIS: REVISTA ESPAÑ OLA DE INVESTIGACIONES SOCIOLÓGICAS 55. 1991. Pág. 47-63 Disponible en https://dialnet.unirioja.es/servlet/articulo?codigo=758600

Cadem. Encuesta Plaza Pública N.³48. (2019). Disponible en https://www.cadem.cl/encuestas/ estudio-no-307-29-de-noviembre-2/

Camila Maia, Ximena Tordini y Luciana Pol (coords.). Los EsTAdos LATINOAMERICANOS FRENTE A LA PROTESTA SOcial. Centro de Estudios Legales y Sociales. (2016). Disponible en https://www. cels.org.ar/web/wp-content/uploads/2017/01/Protesta_social_regional_web-1.pdf

Camilo Burbano. ¿Cómo SE RIGE LA PROTESTA PACífICA EN Colombia? El EJERCICIO y LA GARANTía de UN DERECHO FUndAMENTAL. Fundación Ideas para la Paz. (2008). Disponible en http://www. ideaspaz.org/publications/posts/1704 
Carolina Cardona Quiceno, Edith Johana Puerto Joya, Karen Margarita Beltrán Peñuela, 39 Ernesto Fajardo Pascagaza, Luis Carlos Cervantes Estrada

Comisión Interamericana de Derechos Humanos (CIDH). Capítulo w. Panorama de la situación de derechos humanos en el hemisferio: uso de la fuerza. INFORME ANUAL 2015. Ed. CIDH. (2015).

Congreso de la República de Colombia. LEY 1801 DE 2016. Por la cual se adopta el Código Nacional de Seguridad y Convivencia Ciudadana. Julio 29 de 2016. DO 49.949

Corte Constitucional de Colombia. SENTENCIA C-067 de 03. (M.P. Marco Gerardo Monroy Cabra; febrero 4 de 2003). Disponible en https://www.corteconstitucional.gov.co/relatoria/2003/c-067-03. htm

Doug Mcadam, Sidney Tarrow y Charles Tilly. Dynamics of COnTEnTIOn. Cambridge University Press. (2001).

El Espectador. Muerte de Nicolás NeiRA motiva destitución de Agentes del Esmad. 4 de enero de 2010. Disponible en https://www.elespectador.com/noticias/judicial/muerte-de -nicolas-neira-motiva-destitucion-de-agentes-del-esmad/

Evelyn Huber. Assesments of state strength. Ed. Peter H. Smith. LATIN AmeRICA In COMPARATIVE PERSPECtive: NeW APPROACHES TO MEthods AND ANALYsis. Westview Press. (1995). Pág. 35-69.

Fernando Leal Carretero. Acerca de la teoría. ESPIRAL. ESTUdIOS SOBRE ESTAdo y SOCIEDAD 57. 2013. Pág. 9-38. Disponible en http://espiral.cucsh.udg.mx/index.php/EEES/article/view/357

Fernando Martínez Mercado. Investigación aplicada. Uso de la fuerza. Documento de TRABAJo Nº 4. Centro de Estudios en Seguridad Ciudadana. (2016). Disponible en https://www.cesc.uchile. cl/publicaciones/dt_04_usodelafuerza.pdf

Francesc Guillén Lasierra. Modelos De POlıcía y SEGURIDAd. Bosch. (2016).

Francesc Reales. La gestión de la alteración del orden en espacios públicos: un desafío policial. Revista de Derecho Penal y Criminología 10. 2013. Pág. 493-523. Disponible en http://revistas.uned.es/index.php/RDPC/article/view/24564

Germán Silva García. La teoría del conflicto. Un marco teórico necesario. ProlegómenOS, DeRECHOS Y VALORES 22. Julio-diciembre de 2008. Pág. 29-43. Disponible en http://www.redalyc.org/ pdf/876/87602203.pdf

Instituto Nacional de Derechos Humanos. INFORME ANUAL SITUACIÓN DE LOS DERECHOS HUMANOS EN CHILE. Instituto Nacional de Derechos Humanos. (2013). Disponible en https://bibliotecadigital.indh.cl/handle/123456789/605 
Joel Mendoza-Gómez. La teoría en la investigación científica: marco teórico, modelos y medición. Eds. Karla Annet y Cynthia Sáenz López. Metodología PARA InVESTIGACIONES DE ALTO IMPACTO EN LAS CIENCIAS SOCIALES. Pág. 47-93. (2012).

José Darío Herrera González. LA COMPRENSIÓN DE LO SOCIAL. HORIZONTE HERMENÉUTICO DE LAS CIENCIAS SOCIALES. Editorial Académica Española. (2009).

Marcela Velasco Jaramillo. Cambio institucional y protesta social en Colombia 1964-2000: análisis de series de tiempo. Colombia Internacional 63. Enero de 2006. Pág. 70-87. Disponible en https://doi.org/10.7440/colombiaint63.2006.03

María Eugenia Suárez de Garay. LOS POLICíAS: UnA AVERIGUACIÓN AONTROPOLÓGICA. Iteso. (2016).

Maria Laura Bianciotto. A propósito del ConCEPto de "(sub) CULTURA Policial". Primeros elementos para un posible debate. IX CONGRESO ARgentino de Antropología Social. (2008). Editorial Universidad Nacional de Misiones.

Manuel Góngora Mera. La difusión del bloque de constitucionalidad en la jurisprudencia latinoamericana y su potencial en la construcción del lus Constitutionale Commune Latinoamericano. Eds. Armin von Bogdandy, Héctor Fix-Fierro y Mariela Morales Antoniazzi. Ius Constitutionale Commune en América latina. Rasgos, potencialidades y desafíos. (2014). unam. Pág. 301-327.

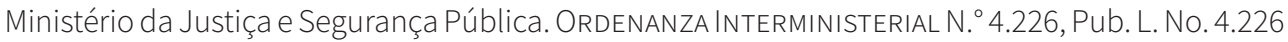
(2010).

Ministerio de Defensa Nacional. RESOLUCIÓN 02903 de 2017. Por la cual se expide el reglamento para el uso de la fuerza y el empleo de armas, municiones, elementos y dispositivos menos letales por la Policía Nacional. (Junio 23 de 2017).

Ministerio del Interiory Seguridad Pública de Chile. MANUAL PARA EL USO DE LA FUERZA CHILE. CIPER Chile. (2019).

Organización de las Naciones Unidas (ONU). PACto INTERNACIONAL DE DERECHOS CIVILES Y PolítICOS. Oficina del Alto Comisionado de las Naciones Unidas. (1976).

Organización de las Naciones Unidas (ONU). CódIGO DE CONDUCTA PARA FUNCIONARIOS ENCARGADOS DE HACER CUMPLIR LA LEY. ONU. (1979).

Organización de los Estados Americanos (OEA). INFORME ANUAL 2019 DE LA COMISIÓN INTERAMERICANA DE DeREChos Humanos. CIDH. (2019). Disponible en http://www.oas.org/es/cidh/docs/anual/2019/indice.asp 
Carolina Cardona Quiceno, Edith Johana Puerto Joya, Karen Margarita Beltrán Peñuela, Ernesto Fajardo Pascagaza, Luis Carlos Cervantes Estrada

Pedro Luis Lorenzo Cadarso. Principales teorías sobre el conflicto social. NoRBA: ReVISTA DE HISTORIA 15. 1995. Pág. 237-253. Disponible en https://dialnet.unirioja.es/servlet/articulo? codigo=241031

Ruth Sautu. Todo es TeORíA. OBJETIVOS y mÉTOdOS de INVESTIGACIÓN. Editorial Lumiere. (2005).

Ruth Sautu, Paula Boniolo, Dalle Pablo y Rodolfo Elbert. La construcción del marco teórico en la investigación social. Ed. Ruth Sautu. Manual de metodología. Construcción del marco TEÓRICO, FORMULACIÓN DE OBJETIVOS Y ELECCIÓN DE LA METOdología. Clacso. (2005).

Santiago Ginés Nabaes Jodar. El concepto de cultura policial. UNIDAD SocıológICA 12. Febreromayo de2018. Pág. 88-97. Disponible en http://unidadsociologica.com.ar/UnidadSociologica 1291.pdf

Secretaría General del Tribunal Administrativo de Boyacá. POR EL USO EXCESIVO DE LA FUERZA PÚBLICa en el Paro nacional Agrario del año 2013, Condenan a la Policía Nacional al pago DE PERJUICIOS. Noviembre 30 de 2017. Disponible en https://www.ramajudicial.gov.co/web/ secretaria-tribunal-administrativo-de-boyaca/-/por-el-uso-excesivo-de-la-fuerza-publicaen-el-paro-nacional-agrario-del-ano-2013-condenan-a-la-policia-nacional-al-pago-de-perjuicios-

Soufiane Ouaarab Essadik. LA REINVENCIÓN DE LA POLICíA: HACIA Un NUEVO PARADIGMA PARA EL PENSAMIENTO DEL GOBIERNO DE LAACTUACIÓN POLICIAL. Universitat Autònoma de Barcelona. (2015).

Tele 13. COMIENZA PREPARACIÓN DE JUICIO ORAL CONTRA EX CARABINERO QUE HIRIÓ A RODRIGO AvILÉs. 3 de enero de 2019. Disponible en https://www.t13.cl/noticia/nacional/comienza -preparacion-juicio-oral-ex-carabinero-hirio-rodrigo-aviles

Wilford Méndez Rojas y José Aristóbulo Rodríguez Salazar. Relación de la policía con el resto de la sociedad: práctica policial, territorio y bios [tesis de maestría, Pontificia Universidad Javeriana]. (2010). 